\title{
Liquidity and default in an exchange economy
}

\author{
Juan Francisco Martinez S. $\quad$ Dimitrios P. Tsomocos ${ }^{\dagger}$
}

November 3, 2016

\begin{abstract}
This paper analyzes various channels of shock transmission in an economy subject to financial frictions, by incorporating liquidity and default effects on asset prices. We develop a framework in which we can assess financial stability policy by introducing a simplified model of exchange and financial intermediation that captures the effects of shocks on financial and real sectors of the economy. The model allows us to explain essential mechanisms and interactions of financial and real economic variables in a comprehensive, yet intuitive fashion. Our results suggest that liquidity and default in the credit markets should be analyzed contemporaneously when financial, monetary and productivity shocks affect financial stability as well as the real economy.
\end{abstract}

Keywords: Default, DSGE, financial stability, liquidity.

JEL Classification codes: D51, D52, E43, E44, E58.

\footnotetext{
${ }^{*}$ Central Bank of Chile. e-mail:jmartinez[at]bcentral.cl

${ }^{\dagger}$ Saïd Business School and St. Edmund Hall, University of Oxford.

${ }^{\ddagger}$ A preliminary version of this paper appeared in 2011 and was entitled "Liquidity effects on asset prices, financial stability and economic resilience." We thank Dimitris Papadimitriou-Doukas and Luis Cabezas for excellent research assistance. We are indebted to CAE Goodhart, Tryphon Kollintzas and Oren Sussman for valuable advice. We also thank Kwangwon Ahn, Raphael Espinoza, Akshay Kotak, Li Lin, Joao and Carlos Madeira, Nuwat Nookhwun, Udara Peiris, Alexandros Vardoulakis and Ji Yan for their helpful comments and suggestions. We are grateful for the discussions at the SAET conference (2011), at Ancao, Faro, Portugal; the Macro Prudential Seminar Series at the Bank of England (2011); The VI Seminar on Risk, Financial Stability and Banking of the Banco Central do Brasil (2011); the Meeting of the Chilean Economists Society at Vina del Mar, Chile, (2011); the ASSA annual meeting at Chicago, US, (2012); the Annual Meeting of the Society for Economic Dynamics at Limassol, Cyprus, (2012); LACEA at Sao Paulo, Brazil, (2014); and the SIIP at the Central Bank of Chile, (2014). Finally, we are grateful to an anonymous referee, whose comments enabled us to improve the work considerably. However, all remaining errors are ours.
} 


\section{Introduction}

The mainstream macroeconomics literature was put to a severe test during the recent global financial crisis. The traditional modelling paradigms incorporate micro-founded representative agent models that embed features of the Real Business Cycle (RBC) and/or NewKeynesian approaches to guide policy makers and central banks. These models have managed to identify sources of economic fluctuations, but also to forecast and delineate the effects of policy interventions. However, given their performance during crisis times, it is arguable that these theoretical tools needed to be extended by incorporating elements that lie at the heart of economic fluctuations: the financial sector and its associated frictions. In this paper, we set out a model to address issues of financial stability and, therefore, assess effects of monetary policy in an integrated framework by introducing liquidity and endogenous default in equilibrium. Our analysis suggest that these frictions are central to explaining the dynamics of financial series during the global financial crisis and assessing alternative policy responses.

The common financial frictions studied in the literature include asymmetric information in the financial markets, which generates inefficient pricing and allocations. Other types of rigidities that are added into these models are essentially nominal. Bernanke et al. (1999), Kiyotaki and Moore (2012) are some of the leading examples in the literature on financial frictions in dynamic stochastic general equilibrium models (DSGE). Various central banks use their insights, because of the pricing and welfare assessment tools that they provide, accompanied by several advantages in calibration and estimation. Bernanke et al. (1999) examine the financial accelerator and the consequent external finance premium effects over the business cycle. Within this framework, the main frictions are price stickiness and costly state verification (i.e., verification of states of nature is costly to the lender and, thus, produces an inefficiency). Kiyotaki and Moore (2012), in turn, include asymmetric information in the form of entrepreneurial moral hazard. As in Bernanke et al. (1999), the transmission of shocks to the real economy depends on the existence of financial markets, asymmetric information and some form of liquidity constraints, via the scarcity of collateral. ${ }^{1}$

The effects of liquidity on financial stability are ambiguous and certainly depend on timing. There are works that indicate that excess of liquidity provision may cause posterior financial instability and others that highlight the effects of sudden liquidity dry-ups. On the one hand, as suggested in Adrian and Shin (2010), and Fostel and Geanakoplos (2008), the over-relaxation of monetary policy and excess of liquidity could lead to over-leverage and, consequently to financial fragility. Conversely, Allen and Gale (2010) show that a negative liquidity shock is associated with asset price volatility and/or increase in defaults. The present study is related to the second strand in the literature. In this context, the introduction of endogenous default illuminates aspects of financial fragility that are intimately connected with liquidity provision and leverage.

Liquidity shocks may be either local or global, or both. Adrian and Shin (2009 and 2011) establish a pattern where monetary policy, domestic funding liquidity and financial stability are linked through balance sheet effects on financial intermediaries. Also, there is empirical and theoretical evidence suggesting a plausible transmission mechanism. For instance, Arora and Cerisola (2000) show strong evidence liquidity transmission through the global monetary policy channel, from advanced to emerging economies that manifests itself in credit spreads. More recently, in an applied theoretical work, Bruno and Shin (2013) illustrate this type

\footnotetext{
${ }^{1}$ Related applications include the analysis of the effects of those frictions in the presence of banking capital requirements, such that of Covas and Fujita (2010), Meh and Moran (2010). Others include informational frictions in bank lending in the form of moral hazard. In particular, Gertler and Karadi (2010), propose a model for the analysis of quantitative easing (QE). This assumes that the source of the friction is the fact that banks have incentives to divert some funding, to alternative uses, instead of lending it. However, one potential disadvantage of this approach is that financial turmoil has to do more with risk taking and/or default than with corporate governance inefficiencies (see Cole (2011)).
} 
of transmission of global monetary policy into emerging economies, through cross-border banking, financial intermediaries balance sheet effects and leverage.

It has been argued in Stein (2012), among others, that financial stability, liquidity and monetary policy are interrelated. The advent of complex trading activities developed by banks and financial institutions obliges regulating authorities to preserve financial stability via interventions in the liquidity channel. Hence, regulation and liquidity management are integral tools of the central banks' regulatory toolkit in the future. We note that Basel III (2011), recognizes this fact and the very definition of macroprudential policy is testimony to this reality. We, therefore, propose a model that integrates liquidity, financial stability and monetary policy in a general equilibrium framework, that allows to study the interactions and spillover effect between financial end economic variables.

As indicated in Brunnermeier et al. (2009), liquidity comprises two dimensions: market and funding. The first is an asset property and the second, an agent characteristic. Herewith, we are able to distinguish both dimensions. On the one hand, we model funding liquidity as the response to monetary policy and, on the other hand, we set market liquidity as the ease with which commodities can be sold. We shall demonstrate that this artefact allows us to assess the effects of asset liquidity on agents' balance sheets and vice versa. Last, market and funding liquidity allow for nominal changes to generate real effects.

We hasten to add that the mere possibility of default underscores the necessity of introducing cash (liquidity) in advance constraints. The interplay of liquidity and default justifies the presence of fiat money as the stipulated medium of exchange. Otherwise, the presence of a monetary sector without the possibility of endogenous default or any other friction in equilibrium may become inessential, without affecting real trade and, eventually, final equilibrium allocations. Put differently, in a model with complete markets and no liquidity constraints money becomes a veil and "the classical dichotomy" is obtained. Hence, monetary policy is neutral in both the short and long run. Indeed, liquidity constraints, or their extreme version of cash-in-advance constraints, are the minimal institutional arrangement to capture a fundamental aspect of liquidity and its interactions with endogenous default generates real effects. In sum, endogenous default in equilibrium becomes compatible with the orderly function of markets.

Given the above considerations, in this paper we develop a theoretical framework that studies financial stability in the presence of financial frictions, with a primary focus on liquidity and default. We provide theoretical and empirical evidence of the interplay of these frictions and their effects on the real and financial sectors of the economy.

In an otherwise standard real business cycle model, we incorporate financial frictions to assess the effects of different shocks on real and financial variables. Hence the interplay of liquidity and default determine the dissemination of shocks over the real economy. The upshot of our mechanism is that, unlike the current literature we do not recourse to informational frictions (e.g. Bernanke et al. (1999) and Kiyotaki and Moore (2012)); instead, the default and liquidity channels characterize directly the transmission mechanism of shocks.

Our model can be interpreted as (i) a closed economy with heterogenous agents, and (ii) a model of international trade. Case (i) consists on a closed economy of households that trade and consume differentiated goods, whereas case (ii) can be interpreted as a reduced (and, of course, highly stylized) form of international economy of two commodity producers. ${ }^{2}$ Both settings include a liquidity provider from the financial sector. In (i), it is interpreted as a representative commercial bank and in case (ii), the liquidity provider can be interpreted as a "global" financial intermediary. In both settings, liquidity is drawn from a central bank

\footnotetext{
${ }^{2}$ Under this interpretation, we assume that exchange rates are fixed.
} 
and/or a financial authority. ${ }^{3}$

Apart from asymmetric information, other financial frictions explored in the financial economics literature comprise the cohabitation of liquidity constraints, agent heterogeneity and default. A detailed analysis of default and its economic implications can be found in the general equilibrium theory with incomplete markets (GEI), such as that of Dubey and Geanakoplos (2003), Dubey, Geanakoplos and Shubik (2005), Shubik and Wilson (1977), Shubik (1999), Tsomocos (2003), and others. Likewise, recent developments in financial markets have motivated a growing literature on liquidity constraints and associated risks. Acharya and Pedersen (2005), Acharya and Richardson (2009), Brunnermeier and Pedersen (2009), Gromb and Vayanos (2002), and Vayanos (2004), have all studied liquidity risks within partial equilibrium models. Alternatively, Goodhart, Sunirand and Tsomocos (2006), Espinoza, Goodhart and Tsomocos (2009), Espinoza and Tsomocos (2015e) analyze liquidity and default in a general equilibrium setting.

Some of the few attempts that try to overcome these issues appear in Leao and Leao (2006), de Walque et al. (2010) and Iacoviello and Neri (2010). While taking into account a detailed financial sector, these studies do not include financing restrictions, liquidity, default, and agent heterogeneity contemporaneously. This paper aims to address this gap in the literature and address systemically their interaction and impact upon the real economy.

In sum, we provide a framework to analyze financial stability under the presence of financial frictions. In particular, we emphasize the interaction of liquidity and endogenous default as we reckon them indispensable components of any stylized framework that purports to address issues of financial stability policy comprehensively. Furthermore, credit spreads are contemporaneous and endogenously determined by default risk and liquidity. In turn, credit spreads are important catalysts of bankruptcies and financial distress, especially during crisis periods.

The paper is organized as follows. The second section presents the model. Section three characterizes the equilibrium of the model. Section four presents the calibration and simulations results. Finally, section five summarizes the main findings and conclusions from our study.

\section{The Benchmark Model}

In this section we introduce a simple dynamic stochastic general equilibrium (DSGE) model with liquidity constraints and endogenous default. The structure of the model and agents' interactions are depicted in figure (1).

This benchmark model provides an environment where we have financial frictions (i.e., money, default and liquidity). Also, it allows us to assess feedback effects among these variables and analyze their effect on asset prices, financial stability, and economic performance. In addition, we can compare the response of the model against various shocks, given different liquidity conditions.

\footnotetext{
${ }^{3}$ In what follows, we describe the model as in case (i). However, conclusions apply to both (i) and (ii), since, as we previously argued, local and global liquidity shocks are transmitted in a rather similar manner. If we were in case (ii) - abstracting from exchange rate considerations - we could easily interpret the liquidity shock as a proxy for international capital flows and, thereby, capture the impact of international shocks on domestic economies.
} 


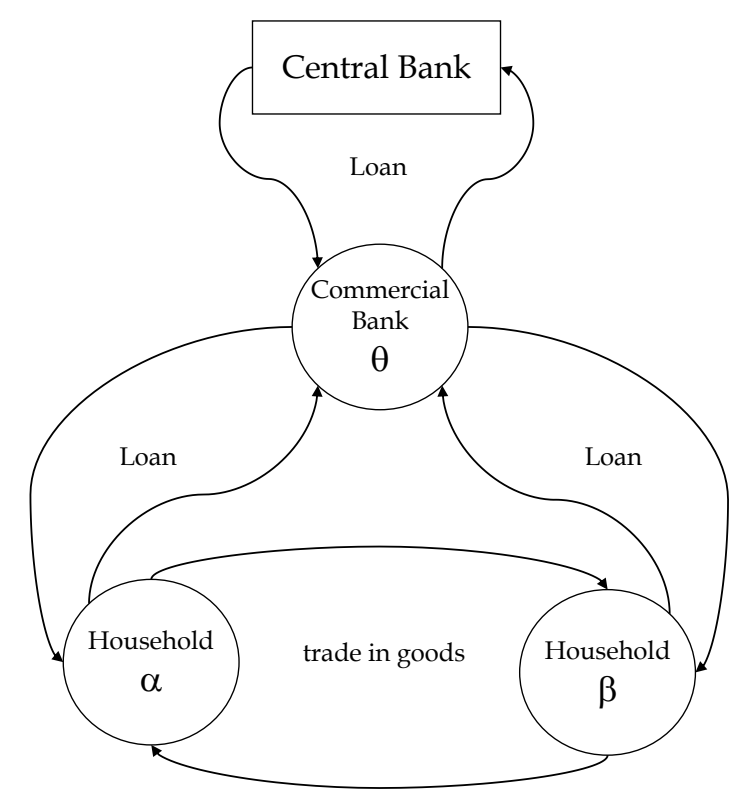

Figure 1: Nominal Flows of the Economy

\subsection{Model setting}

Our model considers infinite dates indexed $(\mathrm{T}=0,1,2, \ldots)$ and two short-lived (1-period) commodities available at each date. We have three types of agents: i) Households ( $\alpha$ and $\beta$ ) that are endowed with, and consume, commodities; ii) a risk-averse set of competitive banks Commercial bank $\theta$ that provides credit (the only financial asset available) and maximizes profits, and iii) a Central Bank that provides liquidity in the $\mathrm{REPO}^{4}$ market by lending to the Commercial bank, and acts as a strategic dummy. ${ }^{5}$ Except for the Central Bank, agents are allowed to default partially on their obligations, subject to a non-pecuniary penalty proportional to the defaulted amount.

We assume that household $\alpha$ is endowed only with good 1 every period, and household $\beta$ is endowed only with good 2. Both of them face cash-in-advance constraints; therefore, to trade and consume, they have to borrow money from the Commercial bank. The latter also borrows money from the Central Bank in the REPO market, because it also faces cash-inadvance constraints as a consequence of the restrictions faced by households. Nevertheless, there exists a liquid portion of commodity endowments that can be used to repay debts and consume. ${ }^{6}$ Additionally, as there is potential variation in commodity prices, monetary variables are deflated by the price index $\mathbb{P}$.

\footnotetext{
${ }^{4}$ Commercial bank repurchase agreements with the Central Bank.

${ }^{5}$ That is, the Central Bank does not optimize any reaction function, and is seen as creating a monetary shock for the rest of the agents.

${ }^{6}$ At this point, it is important to specify the nature of the cash-in-advance constraint. Although agents need to ask for money to the Commercial bank, to finance the fraction of its consumption that cannot be readily financed by the current revenues of commodity sales, the money does not arrive immediately to the pocket of the seller. The seller needs to wait until the beginning of the next period. The economic interpretation is natural and realistic. The buyer extends a document (a check) backed by the amount money in their current account. The check will be converted into cash the next period. Recall that the check only covers the portion of consumption that cannot be financed by the current sales of commodities.
} 
We could think of the Commercial bank $(\theta)$ as a set of competitive banks of the same type. The balance sheet of the Commercial bank is as follows ${ }^{7}$ :

\begin{tabular}{l|l}
\hline \hline A & L \\
\hline Loans to households & $\begin{array}{l}\text { REPO borrowing } \\
\text { Equity }\end{array}$ \\
\hline
\end{tabular}

Similarly, the balance sheet of the Central Bank,

\begin{tabular}{l|l}
\hline \hline A & L \\
\hline REPO loans & Currency (Fiat money) \\
\hline
\end{tabular}

This stylized type of economy implies that the primary function of the Commercial bank is providing liquidity to the households and the Central Bank provides the liquidity to be transferred by the Commercial banks. This is the channel for shocks transmission we will examine. In particular, the financial system we propose contributes to i) credit expansion, ii) optimal risk sharing and iii) facilitating transactions. As proposed by Kashyap et al. (2014), any satisfactory framework should account for all of these oaths.

\subsection{Economy and budget sets}

The economy is composed of $h \in\{\alpha, \beta\}$ households, a representative Commercial bank $\theta$ and a Central Bank.

Households have a positive and stochastic $e_{i_{h}, t}^{h}$ endowment of $i \in\{1,2\}$ types of perishable $l \in L=1,2$ commodities at every period $t$. All the household have only one type of commodity endowment, but have incentives to consume both types. Thus, as they buy good $j$, we have that if $h=\alpha$, then $\left(i_{\alpha}, j_{\alpha}\right)=(1,2)$, and if $h=\beta$, then $\left(i_{\beta}, j_{\beta}\right)=(2,1)$. Preferences- or overall utilities - are described by functions $U$. Financial assets consist of household credit whose interest rate is $r_{t}^{c}$ and Commercial banks' loans taken from the central bank (or REPO market) at an interest rate $r_{t}^{I B}$.

In this economy, households are able to sell a quantity $q_{i_{h}, t}^{h}$ from their stochastic endowment. On the other hand, $b_{j_{h}, t}^{h}$ is the amount of money spent on good $j_{h}$. Thus, agents consume out of the residual of the endowment of goods that they do not sell $\left(e_{i_{h}, t}^{h}-q_{i_{h}, t}^{h}\right)$ and the goods that they buy because they do not have endowment $\left(b_{j_{h}, t}^{h} / p_{j_{h}, t}\right)$. Given a set of securities (i.e. households' credit) and commodity prices $p_{j_{h}, t}$ and $p_{j_{h}, t}$, households make consumption plans in a basket composed of the good they are endowed with $\left(i_{h}\right)$ and the one they need to buy $\left(j_{h}\right), c_{i_{h}, t}^{h}$ and $c_{j_{h}, t}^{h}$; credit demand $\mu_{t}^{h}$; sales of commodity and deliveries against promises $v_{t}^{h}$. Thus, we define the budget set for households as $B\left(p_{1, t}, p_{2, t}, r_{t}^{c}, e_{i_{h}, t}^{h}\right)^{8}$ to be the set of plans $\left(q_{i_{h}, t}^{h}, b_{j_{h}, t}^{h}, \mu_{t}^{h}, v_{t}^{h}\right)$.

Additionally, goods are partially liquefiable and a portion $\left(\lambda_{t}^{h}\right)$ of revenues from their sales can be available instantaneously and consumed. The rest is used to repay debts $\left(1-\lambda_{t}^{h}\right)$. We have that at every date $t$ households are subject to two constraints. First, their repayment of loans must be lower than or equal to the illiquid sales of commodities they drag from the previous period. Second, the households' monetary spending should be lower than or equal to the liquidated portion of commodity sales plus the loans and dividends from the

\footnotetext{
${ }^{7}$ As in Bernanke et. al. (1999), and for the sake of simplicity, customer deposits are not considered in banks' liabilities.

${ }^{8}$ Please notice the simplification in notation.
} 
Commercial bank. ${ }^{9}$ Formally, for the households we have that at every $t>0$ :

$$
\begin{gathered}
v_{t}^{h} \mu_{t-1}^{h} \leq p_{i_{h}, t-1} q_{i_{h}, t-1}^{h} \cdot\left(1-\lambda_{t-1}^{h}\right) \\
b_{j_{h}, t}^{h} \leq \lambda_{t}^{h} \cdot p_{i_{h}, t} q_{i_{h}, t}^{h}+\frac{\mu_{t}^{h}}{1+r_{t}^{c}}+\frac{1-\phi}{2} \Pi_{t}^{\theta}
\end{gathered}
$$

Meanwhile, the Commercial bank $(\theta)$, solicits an amount $\mu_{t}^{\theta}$ of financing from the Central Bank (which injects an amount $M$ to this market at an interest rate $r_{t}^{C B}$ ), and uses it in conjunction with retained earnings to extend loans $l_{t}^{\theta}$ to households. All loans are repaid in the following period. The Commercial bank will optimally choose a rate $v_{t}^{\theta}$ of loans from the Central Bank. In return it expects to receive a fraction $R_{t}$ of the credits provided. To overcome potential losses, the Commercial bank charges a premium on consumer loans with an interest rate $r_{t}^{c}$. We assume that banks retain a portion $\phi$ of their positive profits $\Pi_{t}^{\theta}$.

The Commercial bank is subject to three restrictions, one budget constraint and two identities. First, its credit extensions should not exceed the loans taken from the Central Bank plus its equity $e_{t}^{\theta}$. Second, its profits are positive and defined as the difference between the loans repayment (from the previous periods' credit extensions) and its own repayment to the Central Bank. Third, the equity is accumulated only for one period and comes from the profits retention. Formally, for the Commercial bank at period $t$ we have:

$$
\begin{gathered}
\Pi_{t}^{\theta}=\frac{R_{t} l_{t-1}^{\theta}\left(1+r_{t-1}^{c}\right)}{\mathbb{P}_{t}}-v_{t}^{\theta} \frac{\mu_{t-1}^{\theta}}{\mathbb{P}_{t}} \\
l_{t}^{\theta} \leq \frac{\mu_{t}^{\theta}}{1+r_{t}^{I B}}+e_{t}^{\theta} \\
e_{t}^{\theta}=\phi \Pi_{t}^{\theta}
\end{gathered}
$$

\subsection{Preferences}

In each period the household $h \in\{\alpha, \beta\}$ maximizes its expected utility subject to the budget constraints previously described. That is, by deciding i) how much money to borrow $\left(\mu_{t}^{h}\right)$, ii) how much money to spend in commodities $\left(b_{j_{h}, t}^{h}\right)$, iii) what portion of obligations to repay $\left(v_{t}^{h}\right)$ and iv) how much quantity of the commodity to sell $\left(q_{i_{h}, t}^{h}\right)$, the households optimize their utility function $U_{t}^{h}$, which considers its discounted (by a parameter $\beta^{t}$ ) present benefits from consumption of the goods that they owe (but sell a portion) $u\left(e_{i_{h}, t}^{h}-q_{i_{h}, t}^{h}\right)$ and the goods that they buy from the other agent $u\left(b_{j_{h}, t}^{h} / p_{j_{h}, t}\right)^{10}$. Additionally, its utility contains a non-pecuniary cost proportional (using a default penalty $\tau^{h}$ ) to the defaulted amount of credit (in real terms) that the households obtain from the Commercial bank $\frac{\tau^{h}}{\mathbb{P}_{t}} \operatorname{Max}\left[0,\left(1-v_{t}^{h}\right) \mu_{t-1}^{h}\right]$, which will be discussed shortly in a later section of this paper. Thus, - subject to its budget constraints - every household solves the following program:

$$
\max _{\mu_{t}^{h}, b_{j_{h}, t}^{h}, v_{t}^{h}, q_{i_{h}, t}^{h}} U^{h}=E_{0} \sum_{t=0}^{\infty} \beta^{t}\left\{u\left(e_{i_{h}, t}^{h}-q_{i_{h}, t}^{h}\right)+u\left(\frac{b_{j_{h}, t}^{h}}{p_{j_{h}, t}}\right)-\frac{\tau^{h}}{\mathbb{P}_{t}} \operatorname{Max}\left[0,\left(1-v_{t}^{h}\right) \mu_{t-1}^{h}\right]\right\}
$$

On the other hand, at $t=0$, the Commercial bank $\theta$ maximizes its expected utility described in the previous section. Its decision variables are i) targeted profits $\left(\Pi_{t}^{\theta}\right)$, ii) how much money

\footnotetext{
${ }^{9}$ Notice that in this setting the households own of the bank, but do not control its actions.

${ }^{10}$ From now on we assume that all preferences $u$ are defined by CRRA utility functions, and without loss of generality we assume that the risk aversion parameter $\sigma_{h}$ is equal to 1 . That is, we use logarithmic utility functions.
} 
to borrow $\left(\mu_{t}^{\theta}\right)$, iii) how much money to lend to households $\left(l_{t}^{\theta}\right)$ and iv) what portion of its obligations to repay to the Central Bank $\left(v_{t}^{\theta}\right)$. Thus - subject to its budget constraints - the Commercial bank solves for the present value of the discounted (by a parameter $\hat{\beta}^{t}$ ) utility that contains the utility derived from profits $\left(u\left(\Pi_{t}^{\theta}\right)\right)$ and a non-pecuniary punishment proportional (using a default penalty $\tau^{\omega}$ ) to the (real) defaulted amount of credits taken from the Central Bank $\left(\frac{\tau^{\theta}}{\mathbb{P}_{t}} \operatorname{Max}\left[0,\left(1-v_{t}^{\theta}\right) \mu_{t-1}^{\theta}\right]\right)$. Thus - subject to its budget constraints - the Commercial bank solves the following program:

$$
\max _{\Pi_{t}^{\theta}, \mu_{t}^{\theta}, l_{t}^{\theta}, v_{t}^{\theta}} U^{\theta}=E_{0} \sum_{t=0}^{\infty} \hat{\beta}^{t}\left\{u\left(\Pi_{t}^{\theta}\right)-\frac{\tau^{\theta}}{\mathbb{P}_{t}} \operatorname{Max}\left[0,\left(1-v_{t}^{\theta}\right) \mu_{t-1}^{\theta}\right]\right\}
$$

\section{Timing and flows}

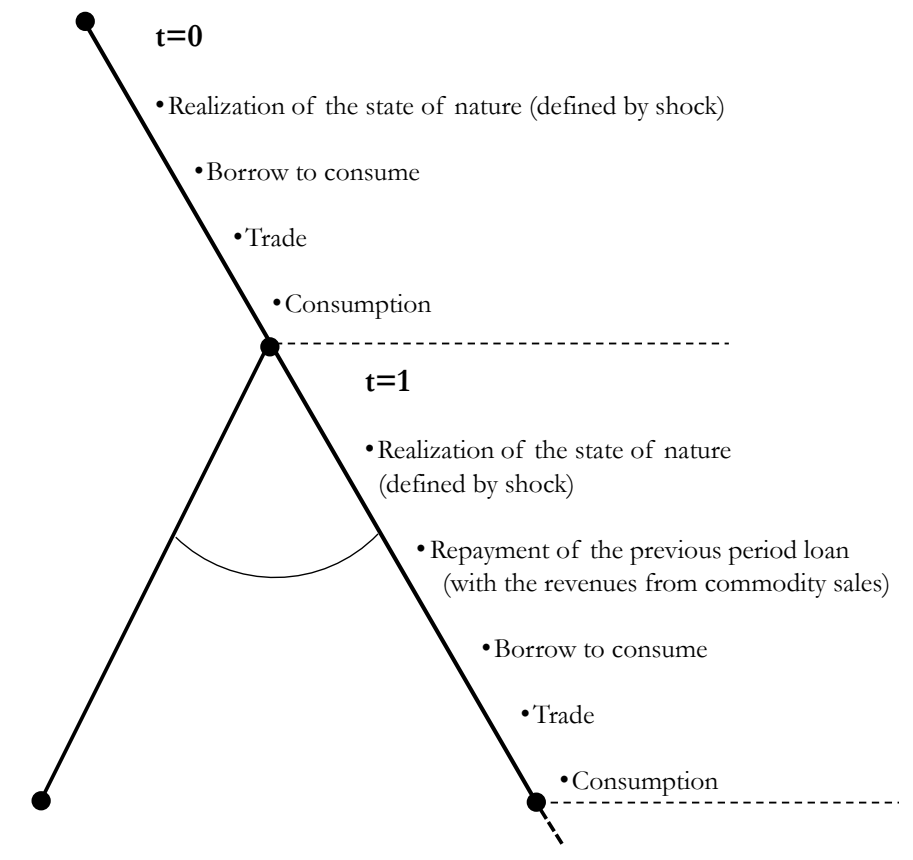

Figure 2: Timing of events

The timing of the different transactions in this simple model is described in Figure (2). This figure describes the order of households' actions. Actions of the bank follow naturally. One can observe that consumers decide after the state of nature is realized how much they are going to borrow, trade and consequently consume. Prices are formed accordingly. From the first period they also decide how much they repay from previous period loans. Table (1) shows the flow of money through time, and also complements the information for banks' actions.

\subsection{Financial frictions}

The financial frictions contained in this analysis include default and liquidity constraints. Other frictions are agent heterogeneity, aggregate uncertainty and money. ${ }^{11}$

\footnotetext{
${ }^{11}$ Agent heterogeneity refers to the households, whose transactions are performed through an exchange of two goods. On the other hand, aggregate uncertainty will be introduced as a monetary shock (or funding liquidity).
} 
Table 1: Monetary flows

\begin{tabular}{l|l|l|l}
\hline \hline \multicolumn{2}{c|}{ Money inflow } & \multicolumn{2}{c}{ Money Outflow } \\
\hline $\begin{array}{l}\text { Commercial } \\
\text { bank }\end{array}$ & Households & $\begin{array}{l}\text { Commercial } \\
\text { bank }\end{array}$ & Households \\
\hline $\begin{array}{l}\text { Loan taken from } \\
\text { Central Bank }\end{array}$ & $\begin{array}{l}\text { Loan taken from } \\
\text { Commercial bank }\end{array}$ & $\begin{array}{l}\text { Loan given to the } \\
\text { households }\end{array}$ & Consumption \\
\hline $\begin{array}{l}\text { Repayment from } \\
\text { households }\end{array}$ & $\begin{array}{l}\text { Revenues from } \\
\text { sales of commodi- } \\
\text { ties }\end{array}$ & $\begin{array}{l}\text { Repayment to } \\
\text { Central Bank }\end{array}$ & $\begin{array}{l}\text { Repayment } \\
\text { Commercial bank }\end{array}$ \\
\hline- & Dividends & Dividends & - \\
\hline
\end{tabular}

\section{Default}

Assets - or credit extensions - are subject to default from the households to the Commercial bank and from the latter to the Central Bank. Default is treated as in Shubik and Wilson (1977) and, more recently, in Dubey, Geanakoplos and Shubik (2005). ${ }^{12}$ In our model, default is prevented by the existence of non-pecuniary penalties, proportional to the size of the unrepaid amount of the contractual obligations. These penalties are subtracted from the utility functions of the households and the Commercial bank and can be interpreted as reputational sanctions the companies may suffer by deciding not to honor their obligations. Therefore, it consists of a deadweight cost from defaulting. This type of default is continuous and strategic. It is continuous since the agents repay partially and they are only punished following a continuous function. ${ }^{13}$ On the other hand, default is strategic because in equilibrium the agents equate the marginal utility from the additional consumption available from defaulting with its costs. We only concentrate on this kind of default, and we acknowledge that there is also a discontinuous default case when agents cannot meet their obligations because the value of the collateral falls below the value of the mortgage/loan. ${ }^{14}$ In this model, for the sake of simplicity, we have no collateral requirement on the loans contract.

A higher default penalty means tighter regulation. Examples of this loss of utility can be found in the registration of defaulting agents in a public list when they are in financial distress. The list - among other financial information - is used by credit-granting institutions in the individuals' credit quality evaluation process. ${ }^{15}$

\section{Liquidity}

Our model considers two sources of liquidity: the funding and market liquidities. The first concept will be represented by inside money, or money injected by the Central Bank, that will determine the interest rates and consequently the cost of credit. This will be described in the next section. On the other hand, market liquidity will be characterized by the liquidity of traded goods.

In this section we follow the work of Espinoza and Tsomocos (2015), which in turn is an extension of Grandmont and Younes (1972). We choose $\lambda_{t}^{\alpha}$ and $\lambda_{t}^{\beta}$ as the parameters for the budget constraint relaxation. Our interpretation is that these parameters characterize the speed of liquidation for goods sold by households. ${ }^{16}$ In steady-state there exists a level that

\footnotetext{
${ }^{12}$ Our approach is also consistent with Hart and Moore (1988) in terms of the incomplete contract features.

${ }^{13}$ See Geanakoplos and Zame (2002) for a case of discrete default: default in collateralized debt. In this case agents default fully when the collateral value is lower than the value of the debt. Consequently collateral is seized.

${ }^{14}$ For a recent application of this type of default in general equilibrium modeling, see Lin et al. (2014)

${ }^{15}$ All amounts - including default penalties - are converted to real by deflating them by an inflation index.

${ }^{16}$ One alternative interpretation is an economy where commodity sales are done through real asset trades that
} 
represents the market liquidity of those goods in the economy. This level will be parameterized later, in the calibration section. Furthermore, in the simulations section we will address how our system responds to a shock in the level of liquidity for each good. We will analyze the case where there is no liquidity and where there is partial symmetric and asymmetric liquidity.

Table 2: Speed of liquidation

\begin{tabular}{l|c|c}
\hline \hline Business sector & Turnover ratio (1) & Speed (2) \\
\hline Services & 29.5 & 0.082 \\
Energy & 15.0 & 0.042 \\
Technology & 10.8 & 0.030 \\
Basic materials & 5.3 & 0.015 \\
Home improvement industry & 4.2 & 0.012 \\
Capital goods & 3.7 & 0.010 \\
\hline \hline
\end{tabular}

(1)Average 2013Q2-2014Q3, in percentage terms.

(2)Turnover ratio on a daily basis.

Source: CSI Market.

When the transactions of goods are not instantaneous, a fraction of the proceedings of goods sales will be expected to be available only at the end of the period. Therefore, receipts associated to the revenues of commodity sales are partly available. This fraction of ready-to-use receipts from sales of commodities is referred to as liquidity. However, following the same argument, as we mentioned previously, a better interpretation for this exogenous parameter is considering it as speed of liquidation. To illustrate this modelling choice, in table (2) we show some values of the turnover ratio of different classes of goods. ${ }^{17}$ Assuming fixed inventory technologies this indicator can be interpreted as the speed of liquidation. In particular, we can observe that - as expected - the speed (or lambda in our case) is higher for services than for capital goods. Thus, in our model, one agent that sells a capital good (e.g. a machine), would have more financing necessities than one who offers services.

We model market liquidity in a reduced form, abstracting from the use of collateral and other modeling devices. Within our framework, market liquidity is approached by goods' liquidity. The argument to relate both is straightforward. When the good that is backing some asset is less liquid, the asset becomes less liquid as well, in the sense that the speed of trade is lower, and if there is any other asset using the previous asset as underlying guarantee, this other asset becomes less liquid too. A natural example is the mortgage market. The asset involved is the mortgage, whereas the good is the physical property (i.e. the collateral). When there is any shock to the liquidity of the property, then the mortgage is affected, as well as the asset backed securities involved. In bad states of nature liquidity binds and a negative shock is transmitted into both asset markets (primary and secondary).

The economy is subject to liquidity shocks in the goods households $\alpha$ and $\beta$ are endowed with. The following equation describes the dynamics of the shocks:

$$
\ln \left(\lambda_{t}^{h}\right)=\rho^{h} \ln \left(\bar{\lambda}^{h}\right)+\left(1-\rho^{h}\right) \ln \left(\lambda_{t-1}^{h}\right)+\epsilon_{h, t}^{\lambda} \quad \text { for } h \in\{\alpha, \beta\}
$$

$\bar{\lambda}^{h}$ remains to be parameterized at the steady-state of the economy. The aggregate liquidity

give the right of equivalent units of consumption. These assets hold the property of having some degree of liquidity: since agents are impatient, the more immediate consumption an asset can generate the more liquid it is.

${ }^{17}$ Turnover is defined as a ratio showing how many times a company's inventory is sold and replaced over a period. 
in the market is defined by the following expression.

$$
\lambda_{t}=\frac{\lambda_{t}^{\alpha} p_{1, t} q_{1, t}^{\alpha}+\lambda_{t}^{\beta} p_{2, t} q_{2, t}^{\beta}}{p_{1, t} q_{1, t}^{\alpha}+p_{2, t} q_{2, t}^{\beta}}
$$

From (7) we can see that the aggregate liquidity index is a weighted average of the individual liquidities of the available goods. There is full aggregate liquidity if and only if there is full individual liquidity for every good in the market.

Liquidity is a market price, and reflects market conditions. The expression (8) relates the demand and supply of money in this economy, and consequently defines market liquidity of goods as a price. Note that $h \in\{\alpha, \beta\}$, and $l=1,2$ are the two commodities in this economy. ${ }^{18}$

$$
\lambda_{t}=\frac{\sum_{l} b_{l, t}-M_{t}}{\sum_{l} p_{l, t} \cdot q_{l, t}^{h}}
$$

\section{Inside money}

Inside money is the instrument of intervention of the Central Bank in the interbank lending market. In our simple case it only represents the liquidity injections via loans that the Central Bank makes to the banking sector. These obligations must exit the system (with accrued interest and net of default) when borrowing commercial banks repay their obligations. We model inside money shocks as changes in the level of open market operations (OMOs).

$$
M_{t}=\eta_{t}^{C B} \bar{M}
$$

Where

$$
\ln \left(\eta_{t}^{C B}\right)=\rho^{C B} \ln \left(\bar{\eta}^{C B}\right)+\left(1-\rho^{C B}\right) \ln \left(\eta_{t-1}^{C B}\right)+\epsilon_{C B, t}
$$

and $\bar{\eta}^{C B}=1$ is the monetary operations' gross growth at the steady-state of the economy.

\subsection{Rest of the model}

\section{Stochastic endowment}

Since the focus of our model is on financial stability, we allow for endowment economy with trade. This way we simplify the calculations and concentrate just on the part of the model that allows us to take into account the price and endowment divergences. We assume a stochastic endowment for each agent. Therefore, the only way to smooth consumption across agents is through commodities trading between the households. The following equation describes the form of the stochastic endowment:

$$
\ln \left(e_{l, t}^{h}\right)=\rho_{e}^{h} \ln \left(\bar{e}_{l}^{h}\right)+\left(1-\rho_{e}^{h}\right) \ln \left(e_{l, t-1}^{h}\right)+\epsilon_{h, t}^{e} \quad \text { for } h \in\{\alpha, \beta\} \quad \text { and } l \in\{1,2\}
$$

This endowment is a part of the fundamental value in this simplified economy. That is how fundamentals should explain the asset prices and economic variable dynamics. However, in this paper we concentrate on how the financial and real variables are affected not by the endowment, but by the liquidity of goods.

\footnotetext{
${ }^{18}$ For the sake of simplicity and without loss of generality, we also assume that already distributed.
} 


\section{Inflation}

The gross rate of inflation obeys the following equation:

$$
\mathbb{P}_{t}=\frac{P_{t}}{P_{t-1}}
$$

After obtaining the right weights for the two commodities present in the consumption basket (see Appendix 1 for more details), we are able to compute a Laspeyres type of inflation index.

$$
\mathbb{P}_{t}=\left(1+\pi_{t}\right)=\frac{p_{1, t} \bar{q}_{1}^{\alpha}+p_{2, t} \bar{q}_{2}^{\beta}}{p_{1, t-1} \bar{q}_{1}^{\alpha}+p_{2, t-1} \bar{q}_{2}^{\beta}}
$$

In our case, $\mathbb{P}$ is the gross inflation index, whereas $\pi$ is the net inflation growth. This is calibrated to the target level of the Central Bank (see calibration section for more details). From the previous calculations, we have thus constructed the inflation index as a function of the variables in our model. In the section related to characterization of the equilibrium, we are going to see the quantity theory of money proposition, as a function of the price index we have defined and the money spent in the system each period.

In the simulations section we show the response of inflation to different financial shocks.

\section{Market clearing conditions}

The economy implicit in our model contains three different markets: goods, consumer loans and REPO operations. These markets determine prices by equating demand and supply.

\section{Goods market}

The (fiat) money spent in the goods market is equal to the value of the supply of goods 1 and 2 at each period.

$$
\begin{aligned}
& b_{1, t}^{\beta}=p_{1, t} q_{1, t}^{\alpha} \\
& b_{2, t}^{\alpha}=p_{2, t} q_{2, t}^{\beta}
\end{aligned}
$$

\section{Consumer loans market}

The households' loans demand equals the supply of funds offered by the Commercial bank at each period.

$$
1+r_{t}^{c}=\frac{\mu_{t}^{\alpha}+\mu_{t}^{\beta}}{l_{t}^{\theta}}
$$

\section{REPO Market}

The Commercial bank's loan demand equals the supply of funds offered by the Central Bank at each period.

$$
1+r_{t}^{I B}=\frac{\mu_{t}^{\theta}}{M_{t}}
$$

\section{Rational expectations}

The following conditions indicate that the Commercial bank is accurate in its expectations of the repayments on the loans extended. Therefore, the expected repayment rate for bank $\theta$ is given by the following expression: 


$$
R_{t}= \begin{cases}\frac{v_{t}^{\alpha} \mu_{t-1}^{\alpha}+v_{t}^{\beta} \mu_{t-1}^{\beta}}{\mu_{t-1}^{\alpha}+\mu_{t-1}^{\beta}}, & \text { if } \mu_{t-1}^{\alpha}+\mu_{t-1}^{\beta}>0 \\ \text { arbitrary, } & \text { if } \mu_{t-1}^{\alpha}+\mu_{t-1}^{\beta}=0\end{cases}
$$

Conversely, the Central Bank acts as a strategic dummy and does not form any kind of expectations about the Commercial bank's repayment.

\section{Equilibrium}

In this section we define the equilibrium of the model. This definition depends upon the definitions of: decision variables, macroeconomic variables, parameters and budget sets. The endogenous variables and variables being shocked are defined mainly to keep track of the simulation procedure we perform afterwards. ${ }^{19}$

\subsection{Definition of Equilibrium}

Given the previous definitions we are able to define the FSMLD (financial stability with money, liquidity and default) equilibrium, for the short as well as the long run. In our case in the long run the economy converges to its steady-state.

\section{Short run}

In our model, $\left(\Sigma^{\alpha}, \Sigma^{\beta}, \Sigma^{\theta}, \kappa\right)$ is a short run FSMLD iff:

(i) All agents optimize given their budget sets:

(a) $\Sigma^{h} \in \operatorname{Argmax}_{\Sigma^{h} \in B^{h}(\kappa)} U\left(C^{h}\right)$, for $\mathrm{h} \in\{\alpha, \beta\}$ and $\forall t \in T$.

(b) $\Sigma^{\theta} \in \operatorname{Argmax}_{\Sigma^{\theta} \in B^{\theta}(\kappa)} U\left(\Pi^{\theta}\right), \forall t \in T$.

(ii) All markets (14)-(17) clear.

(iii) Expectations are rational, (i.e. (18) holds).

\section{Long run}

In our model, in steady-state, in addition to the conditions for a short run equilibrium, in order to obtain a long run FSMLD, we need that:

(i) All real and nominal variables do not grow, thus

$$
x_{t}=x, \quad \forall t \in T \quad x_{t} \in X_{t}=\left\{\Sigma^{\alpha}, \Sigma^{\beta}, \Sigma^{\gamma}, \kappa\right\}
$$

(ii) The economy is not subject to any shock, thus

$$
e_{t}=0, \quad \forall t \in T \quad e_{t} \in\left\{\epsilon_{C B, t}, \epsilon_{\alpha, t}^{\lambda}, \epsilon_{\beta, t}^{\lambda}, \epsilon_{\alpha, t}^{e}, \epsilon_{\beta, t}^{e}\right\}
$$

That is, there are no shocks on the monetary base, liquidity or endowments.

\subsection{Characterization of Equilibrium}

In this subsection we are going to use the results obtained from the First Order Conditions (FOCs) in order to get insights about important relationships that are maintained in our model: money non-neutrality, Fisher effect, quantity theory of money, on the verge condition and interest rates under default and no default. Appendix 3 contains proofs of these propositions.

\footnotetext{
${ }^{19}$ For model details such as decision, macroeconomic and endogenous variables; parameters; shocks and budget sets, see Appendix 2.
} 


\section{Proposition 1: Money non-neutrality}

This proposition implies that if there is a non-zero monetary operation by the Central Bank (i.e. $M_{t} \neq M_{t}^{\prime} \Rightarrow r_{t}^{c} \neq r_{t}^{c \prime}$, from market clearing conditions), monetary policy is not neutral in the short run. Therefore, it affects the consumption and consequently real variables.

Suppose that for $\alpha, \beta \in H, b_{t}^{h}>0$, for $l \in L, \lambda_{t}^{h} \in[0,1)$ and some state of nature defined by the set of shocks at $t$. We have that at a FSMLD,

$$
r_{t}^{c} \leq r_{t}^{c \prime} \text {, and for a given } \lambda_{t}^{\alpha} \geq \lambda_{t}^{\alpha \prime} \Rightarrow q_{1, t}^{\alpha} \geq q_{1, t}^{\alpha \prime}
$$

Note that by symmetry the proposition also holds for household $\beta$.

We have two extreme cases to analyze ${ }^{20}$ :

i. If $\lambda_{t}^{\alpha}=1$, we have no liquidity restrictions. Therefore, there are no incentives to borrow money and monetary policy is neutral. We can observe this directly from the following equation.

$$
\frac{\partial u\left(c_{1, t}^{\alpha}, c_{2, t}^{\alpha}\right)}{\partial c_{1, t}^{\alpha}}=\frac{\partial u\left(c_{1, t}^{\alpha}, c_{2, t}^{\alpha}\right)}{\partial c_{2, t}^{\alpha}} \frac{p_{1, t}}{p_{2, t}}
$$

It should be noted that in this case default makes no sense, since there is nothing to default on. Thus, if there is full liquidity we are at the standard Edgeworth 2-agents 2 -good case, where - in equilibrium -, the ratio of marginal utilities equates the ratio of prices.

ii. If $\lambda_{t}^{\alpha}=0$, we have that monetary policy is not neutral. This is the usual cash-inadvance setting, and the proof is analogous to the previous one.

$$
\frac{\partial u\left(c_{1, t}^{\alpha}, c_{2, t}^{\alpha}\right)}{\partial c_{1, t}^{\alpha}}=\frac{1}{1+r_{t}^{c}} \frac{\partial u\left(c_{1, t}^{\alpha}, c_{2, t}^{\alpha}\right)}{\partial c_{2, t}^{\alpha}} \frac{p_{1, t}}{p_{2, t}}
$$

Notice that in this case there are liquidity restrictions. Thus, the presence (absence) of default plays a role in the determination of equilibrium. However, given an interest rate - that itself contains a premium - default does not affect condition (20). In this case, the usual equality obtained in the Edgeworth economy (19) is weighted by (the inverse of) the funding cost (i.e. gross commercial interest rate).

\section{Proposition 2: Fisher effect}

Suppose that for $\alpha, \beta \in h, b_{t}^{h}>0$, for $l \in L, \lambda_{t}^{h} \in[0,1)$ and some state of nature defined by the set of shocks at $t$. We have that at a FSMLD, for agent $\alpha$, we have,

$$
\left(\frac{1}{1-\lambda_{t}^{\alpha}}\left(\frac{\frac{\partial u\left(c_{1, t}^{\alpha}, c_{2, t}^{\alpha}\right)}{\partial c_{1, t}^{\alpha}}}{\frac{\partial u\left(c_{1, t}^{\alpha}, c_{l, t}^{\alpha}\right)}{\partial c_{2, t}^{\alpha}}} \frac{p_{2, t}}{p_{1, t}}-\lambda_{t}^{\alpha}\right)\right)^{-1}=\left(1+r_{t}^{c}\right)
$$

whereas, for agent $\beta$, we have

$$
\left(\frac{1}{1-\lambda_{t}^{\beta}}\left(\frac{\frac{\partial u\left(c_{1, t}^{\beta}, c_{2, t}^{\beta}\right)}{\partial c_{2, t}^{\prime}}}{\frac{\partial u\left(c_{1, t}^{\beta}, c_{l, t}^{\beta}\right)}{\partial c_{1, t}^{\beta}}} \frac{p_{1, t}}{p_{2, t}}-\lambda_{t}^{\beta}\right)\right)^{-1}=\left(1+r_{t}^{c}\right)
$$

Taking logarithms on both sides, this proposition roughly indicates that nominal interest rates are approximately equal to real interest rates plus relative pricing and liquidity premium. On the one hand, real interest rates are obtained in the form of a pricing kernel, and

\footnotetext{
${ }^{20}$ These are equivalent for agent $\beta$.
} 
inflation is embedded in the relative pricing. On the other hand, a lower market liquidity (which is determined by $\lambda_{t}^{h}, h \in\{\alpha, \beta\}$ ) increases the interest rates, hence credit costs too. In this framework, all other things equal, a lower market liquidity translates into a higher demand for credit, hence an increase in interest rates. Thus, the Fisher effect explains how nominal prices are linked directly to consumption. Note that default premium is embedded in interest rates and it will be clearer in propositions 4 and 5 .

\section{Proposition 3: Quantity theory of money}

Assume no money is carried over, except for repayment purposes, since resources cannot be accumulated. ${ }^{21}$ In an interior FSMLD equilibrium, $\forall t \in T$

$$
\left(1-\lambda_{t}^{\alpha}\right) p_{1, t} q_{1, t}^{\alpha}+\left(1-\lambda_{t}^{\beta}\right) p_{2, t} q_{2, t}^{\beta}=M_{t}
$$

Thus, the model possesses a non-trivial quantity theory of money, where prices and quantities are determined simultaneously.

Fisher's (1911) quantity theory of money proposition states that

$$
P_{t} Q_{t}=M_{t} V_{t}
$$

It implies that money supply has a direct, proportional relationship with the price level, where $P_{t}$ stands for the price index, $Q_{t}$ is an index of the real value of final expenditures, $M_{t}$ is the total amount of money in circulation each period, and $V_{t}$ is the average velocity of money in the market.

We already know $P_{t}$ from equation (40). However, we still need to define the other variables in the expression. We need to define the real value of final expenditures $Q_{t}$. To achieve this, we write,

$$
Q_{t}=\omega_{1}^{q} \frac{q_{1, t}^{\alpha}}{\bar{q}_{1}^{\alpha}}+\omega_{2}^{q} \frac{q_{2, t}^{\beta}}{\bar{q}_{2}^{\beta}}
$$

whereas the corresponding weight for traded quantities is

$$
\begin{gathered}
\omega_{1}^{q}=\frac{p_{1, t} \bar{q}_{1}^{\alpha}\left(\bar{p}_{1} \bar{q}_{1}^{\alpha}+\bar{p}_{2} \bar{q}_{2}^{\beta}\right)}{p_{1, t} \bar{q}_{1}^{\alpha}+p_{2, t} \bar{q}_{2}^{\beta}} \\
\omega_{2}^{q}=\frac{p_{2, t} \bar{q}_{2}^{\beta}\left(\bar{p}_{1} \bar{q}_{1}^{\alpha}+\bar{p}_{2} \bar{q}_{2}^{\beta}\right)}{p_{1, t} \bar{q}_{1}^{\alpha}+p_{2, t} \bar{q}_{2}^{\beta}} .
\end{gathered}
$$

From the previous expression we can observe that the weights in this case add up to the total expenditures amount in steady-state (the baseline year). Therefore, we define $Q_{t}$ as the average portion of expenditures in each year, by considering the average price and quantity changes in each period, i.e.

$$
Q_{t}=\frac{\left(p_{1, t} q_{1, t}^{\alpha}+p_{2, t} q_{2, t}^{\beta}\right)\left(\bar{p}_{1} \bar{q}_{1}^{\alpha}+\bar{p}_{2} \bar{q}_{2}^{\beta}\right)}{p_{1, t} \bar{q}_{1}^{\alpha}+p_{2, t} \bar{q}_{2}^{\beta}} .
$$

From the quantity theory of money proposition, we know that the money in the system every period is defined as follows:

$$
M_{t}=\left(1-\lambda_{t}^{\alpha}\right) p_{1, t} q_{1, t}^{\alpha}+\left(1-\lambda_{t}^{\beta}\right) p_{2, t} q_{2, t}^{\beta}
$$

\footnotetext{
${ }^{21}$ Without loss of generality we also assume that bank profits are already distributed to the households.
} 
If we use the aggregate liquidity definition in equation (7), we then have

$$
M_{t}=\left(1-\lambda_{t}\right)\left(p_{1, t} q_{1, t}^{\alpha}+p_{2, t} q_{2, t}^{\beta}\right)
$$

The only remaining term to define in expression (24) is $V_{t}$, the velocity of money. In our case, it is equal to $1 /\left(1-\lambda_{t}\right)$ so

$$
V_{t}=\frac{1}{\left(1-\lambda_{t}\right)} .
$$

That is, greater liquidity of goods increases the actual amount of money in the economy, and therefore, the proportion of the Central Bank's money decreases. In this sense, to maintain the level of transactions - with a fixed amount of money - there is the need to increase the speed of transactions.

To illustrate this result, we present a plot in figure (3) with the yearly variations in the velocity of money, calculated for a selected group of emerging economies. ${ }^{22}$ From our result in (31) our hypothesis is that velocity should be proportional to market liquidity, as we interpret it. The plot shows a remarkable decrease in velocity during the crisis period (arbitrarily situated at the second half of 2007). Following this period, after the second half of 2009 there was a recovery of velocity. However, after the beginning of 2011 we observe a new decrease in this variable. This result suggests, following our hypothesis in (31), that the 2007-2008 crisis in emerging economies was clearly associated with a decrease in market liquidity. Furthermore, we can assess these variations by looking at monetary aggregates. This result highlights the need to consider money in the analysis of financial phenomena.

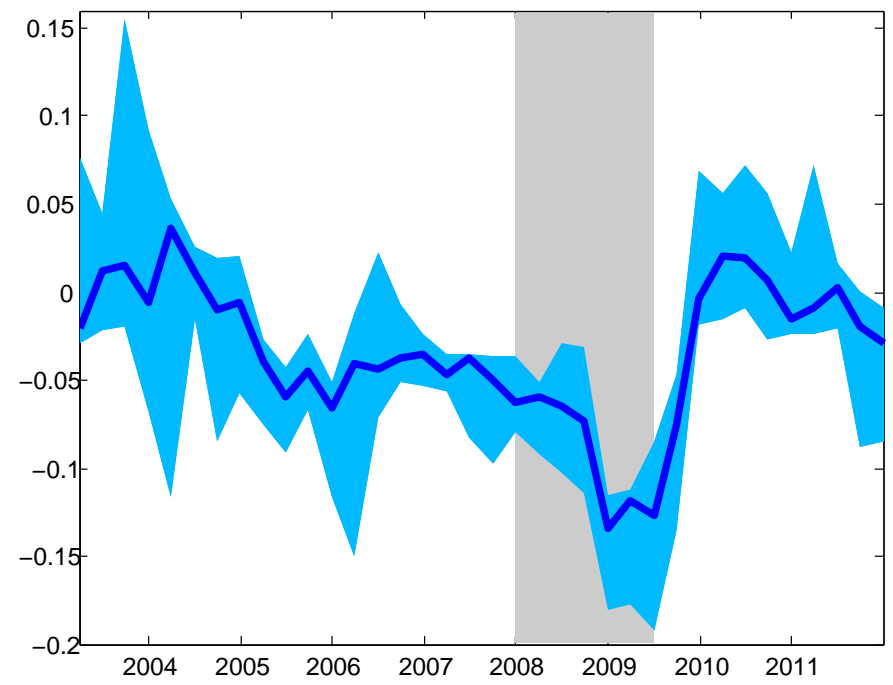

Figure 3: Money velocity yearly changes on quarterly data for a group of emerging countries. Calculated as the ratio of nominal GDP over M2. Source: IFS database, International Monetary Fund. Shaded sky blue zone represents first and third quartile, solid line is the median. Shaded gray zone represents NBER's Business Cycle date for Great Recession.

Additionally, our model provides an explicit expression for a Fisher quantity theory of money relation. The importance of this proposition in our benchmark economy lies in the fact that despite our model being very parsimonious, it provides a non-trivial determination of prices

\footnotetext{
${ }^{22}$ The emerging countries that we have considered are: Brazil, Chile, Czech Republic, Iceland, Korea, Poland and Republic of Turkey.
} 
and quantities.

Our model is in stark contrast with the classical RBC representative agent model, wherein traded quantities are fixed since there is no trade in equilibrium. Hence, any monetary policy change has nominal effects only as it merely changes prices. The upshot of our argument is that when one introduces liquidity and default, this class of models is non-dichotomous.

\section{Proposition 4: On the verge condition}

Suppose that for $\alpha, \beta \in H, b_{t}^{h}>0$, for $l \in L, \lambda_{t}^{h} \in[0,1)$, and some state of nature defined by the set of shocks at $t$. We have that at a FSMLD, the on-the-verge condition for default penalties, for agents $\alpha, \beta$ and bank $\theta$, respectively, is given by

$$
\begin{gathered}
\frac{1}{1+r_{t}^{c}} \frac{\partial u\left(c_{1, t}^{\alpha}, c_{2, t}^{\alpha}\right)}{\partial c_{2, t}^{\alpha}} \frac{1}{p_{2, t}}=\beta \mathbb{E}_{t}\left(\frac{\tau^{\alpha}}{\mathbb{P}_{t+1}}\right) \\
\frac{1}{1+r_{t}^{c}} \frac{\partial u\left(c_{1, t}^{\beta}, c_{2, t}^{\beta}\right)}{\partial c_{1, t}^{\beta}} \frac{1}{p_{1, t}}=\beta \mathbb{E}_{t}\left(\frac{\tau^{\beta}}{\mathbb{P}_{t+1}}\right) \\
\left.\frac{\partial u\left(\Pi_{t}^{\theta}\right)}{\partial \Pi_{t}^{\theta}}=\tau^{\theta}\left(1-\phi \hat{\beta} \mathbb{E}_{t} \frac{R_{t+1}\left(1+r_{t}^{c}\right)}{\mathbb{P}_{t+1}}\right)\right)
\end{gathered}
$$

In the steady-state, the optimal default penalties for agents $\alpha, \beta$ and bank $\theta$ in FSMLD will be determined as follows, ${ }^{23}$

$$
\begin{array}{r}
\frac{1}{1+\bar{r}^{c}} \frac{\partial u\left(\bar{c}_{1}^{\alpha}, \bar{c}_{2}^{\alpha}\right)}{\partial c_{2}^{\alpha}} \frac{1}{\bar{p}_{2}}=\beta \tau^{\alpha} \\
\frac{1}{1+\bar{r}^{c}} \frac{\partial u\left(\bar{c}_{1}^{\beta}, \bar{c}_{2}^{\beta}\right)}{\partial c_{1}^{\beta}} \frac{1}{\bar{p}_{1}}=\beta \tau^{\beta} \\
\frac{\partial u\left(\bar{\Pi}^{\theta}\right)}{\partial \Pi^{\theta}}=\tau^{\theta}\left(1-\phi \hat{\beta} \bar{R}^{\theta}\left(1+\bar{r}^{c}\right)\right)
\end{array}
$$

These conditions imply that the optimal amount of default is attained when the marginal utility of defaulting equals the marginal dis-utility. Notice that market liquidity is not present in the default trade-offs. However, it should be implicit in the determination of equilibrium interest rates. An illustrative example indicates that - for instance - if there is an increase in funding costs, through interest rates -given that the default cost is fixed (i.e. penalties) - this will push upwards the consumption marginal utilities, to compensate. Thus, agents would value more consumption than repayment, and consequently delivery rates would be reduced.

There are three cases to analyze for agents $\alpha$ and $\beta$, and bank $\theta$ (in this case $\hat{h} \in \hat{H}=$ $\{\alpha, \beta, \theta\})$.

i. $u^{\hat{h} \prime}(\cdot)>\tau^{\hat{h}}$. This condition implies that the agent $\hat{h} \in \hat{H}$ will default completely. Consequently, the asset will not be traded.

ii. $u^{\hat{h} \prime}(\cdot) \ll \tau^{\hat{h}}\left(\right.$ i.e. $\left.\tau^{\hat{h}} \rightarrow \infty\right)$. This condition implies that buyers will anticipate full delivery, but sellers of the asset (i.e. borrowers) will realize that with some probability they will not be able to avoid a crushing penalty. Consequently, the asset will not be traded.

iii. $u^{\hat{h} \prime}(\cdot)=\tau^{\hat{h}}$. An intermediate level of default penalties can make everyone better off. This condition implies that there is trade in assets.

\footnotetext{
${ }^{23}(\bar{\cdot})$ indicates the variable's steady-state value.
} 


\section{Proposition 5: Interest rates under default and no default}

This condition implies that in case there is default the interest rates are defined to be positive, to align default incentives.

Suppose that for $\alpha, \beta \in H, b_{t}^{h}>0$, for $l \in L, \lambda_{t}^{h} \in[0,1)$ and some state of nature defined by the set of shocks at $t$. We have that at a FSMLD, the interest rates when default is positive are $r_{t}^{c}, r_{t}^{I B}>0$. Furthermore, if exists partial default $\left(\mathbb{E}_{t}\left(R_{t+1}\right)<1\right)$, then the equation (56) indicates that $0<r_{t}^{I B}<r_{t}^{c}$. However, when there is no default, the Friedman rule obtains and $r_{t}^{c}=r_{t}^{I B}=0$. In this case, risk premiums do not exist. Thus, there are no motives for financial intermediation. Furthermore, as there are no liquidity restrictions, this is the standard Edgeworth economy case.

\section{Solution of the model}

In this section, we describe the different steps we follow in order to find the numerical solution of our model and also generate the impulse response functions of the shocks affecting the variables. Henceforth, we use a CRRA utility function for the households and the bank with coefficients of relative risk aversion $\sigma_{h}$ and $\sigma_{\theta}$, respectively, equal to one. That is, a logarithm utility function for each one, except when otherwise stated. The solution method includes the parameterization and calibration, the steady-state solution and the simulations.

\subsection{Calibration}

We calibrate our model for three different cases. The first is the pure cash-in-advance economy, when goods (real assets) are not liquid. The second case is the one with asymmetric liquidity. The third case is symmetric in liquidity with slightly higher overall liquidity than the asymmetric case. ${ }^{24}$

Table 3: Parameterization

\begin{tabular}{c|c|c|c}
\hline \hline Parameter & Basic model & $\lambda^{\alpha}=0.5, \lambda^{\beta}=0.2$ & $\lambda^{\alpha}=0.5, \lambda^{\beta}=0.5$ \\
\hline $\bar{\eta}^{C B}$ & 1 & 1 & 1 \\
$\tau^{\alpha}$ & 0.3525 & 0.22915 & 0.17625 \\
$\tau^{\beta}$ & 0.3525 & 0.22915 & 0.17625 \\
$\tau^{\theta}$ & 8 & 8 & 8 \\
$\bar{e}_{1}^{\alpha}$ & 2 & 2 & 2 \\
$\bar{e}_{2}^{\beta}$ & 2 & 2 & 2 \\
$\beta$ & 0.97 & 0.97 & 0.97 \\
$\hat{\beta}$ & 0.98 & 0.98 & 0.98 \\
$\rho^{C B}$ & 0.5 & 0.5 & 0.5 \\
$\rho^{\alpha}$ & 0.5 & 0.5 & 0.5 \\
$\rho^{\beta}$ & 0.5 & 0.5 & 0.5 \\
$\rho^{\theta}$ & 0.5 & 0.5 & 0.5 \\
$\bar{M}$ & 5 & 5 & 5
\end{tabular}

In this calibration exercise we choose the parameters so that in the steady-state annual

\footnotetext{
${ }^{24}$ In the case without default, we use the same parameters of the basic model.
} 
Commercial bank interest rate is $7.9 \% .{ }^{25}$ Additionally, we can observe from table 3 , that we have set the steady-state monetary operations to be constant. We will shock this variable afterwards. It is worth remembering that the Central Bank in our case acts as a strategic dummy, and we want to see the effect of its actions in the presence of different liquidity environments and default.

The bank's discount factor parameter is set to $0.98 .^{26}$ We fix households' discount factor at 0.97 , because they are more impatient and their interest rates should be higher due to default risk.

Default of households and Commercial bank are calibrated by defining parameters $\tau^{h}$ and $\tau^{\theta}$. The targeted variables are repayment rates and consequently interest rates.

Finally, we set the persistence of the monetary shock parameter to 0.5 following to Christiano et al. (1998). We equalize the persistence of every shock to this monetary shock to have every shock on the same scale. This will help us in the posterior simulations section.

\subsection{Steady-state}

It is a non-linear system of equations that we solve by using the standard Newton-Raphson algorithm. As our problem is relatively simple and our functions are continuous and smooth, this technique presents no problems. In table (4) we present the steady-state solution.

We obtain a robust steady-state equilibrium since it is calculated in an interior region of the equilibria. This is given by an economically sensible array of parameters that avoids nonconvexities or severe non-linearities. Recall that the utilities for all the agents are concave and budget sets are convex.

Central Bank interest rate is set to $2.1 \%$ per annum. ${ }^{27}$ Commercial bank interest rate is calibrated to $7.9 \%$ per annum. Inflation is set to an average of $0 \%$ per year, which is implied by the initial money balance of our exercise.

Given our calibration, we have a symmetric allocation and pricing equilibrium in steadystate, except in the asymmetric liquidity case. The purpose is to set the easiest benchmark case to be compared in the presence of shocks in the simulations section. Thus, we can observe direction and magnitude of the divergences from the steady-state. In the case with asymmetric liquidity, prices are higher for the less liquid good, as we would expect. The relatively scarcer the good, the higher the price. Following the same argument, trade is lower in the less liquid good.

Consistent with propositions 2 and 4 , average repayment rates are higher in an economy where commodities have more liquidity. The mechanism works through interest rates (proposition 2) which should be lower than in the more liquid economy, combined with lower incentives to default if rates are lower (proposition 4). In particular, the repayment rates are

\footnotetext{
${ }^{25}$ The lending interest rate observed in emerging and developing countries between 2008 and 2012 is roughly $13 \%$ (World Development Indicator, World Bank). The difference with respect to the chosen value is due to the fact that we do not take into account operational and administrative costs (which account for about $5 \%$ for the same countries).

${ }^{26}$ Taken from King and Rebelo (1999). They obtain this parameter by equating steady-state real interest rate with the average return of capital in the economy, whereas the latter is approximated using the average return on the S\&P 500 index.

${ }^{27}$ This value is similar to the emerging and developed market monetary policy rates index between 2008 and 2012 (Global Monetary Policy Rate Index, in Central Bank News, Peter Nielsen (2012)).
} 
Table 4: Steady-state

\begin{tabular}{c|c|c|c|c}
\hline \hline Variable & Basic model & $\lambda^{\alpha}=0.5$ & $\lambda^{\alpha}=0.5$ & Full liquidity \\
& & $\lambda^{\beta}=0.2$ & $\lambda^{\beta}=0.5$ & \\
\hline$p_{1}$ & 2.817 & 4.248 & 5.523 & 0.524 \\
$p_{2}$ & 2.817 & 4.299 & 5.523 & 0.524 \\
$r^{c}$ & 0.079 & 0.079 & 0.079 & - \\
$r^{I B}$ & 0.024 & 0.024 & 0.024 & - \\
$R$ & 0.949 & 0.949 & 0.949 & - \\
$\mu^{\alpha}$ & 2.857 & 2.181 & 2.857 & - \\
$b_{2}^{\alpha}$ & 2.710 & 4.169 & 5.420 & 0.524 \\
$v^{\alpha}$ & 0.949 & 0.956 & 0.949 & - \\
$q_{1}^{\alpha}$ & 0.962 & 0.981 & 0.981 & 1.000 \\
$\mu^{\beta}$ & 2.857 & 3.531 & 2.857 & - \\
$b_{1}^{\beta}$ & 2.710 & 4.169 & 5.420 & 0.524 \\
$v^{\beta}$ & 0.949 & 0.945 & 0.949 & - \\
$q_{2}^{\beta}$ & 0.962 & 0.970 & 0.981 & 1.000 \\
$\Pi^{\theta}$ & 0.420 & 0.420 & 0.420 & - \\
$\mu^{\theta}$ & 5.119 & 5.119 & 5.119 & - \\
$l^{\theta}$ & 5.294 & 5.294 & 5.294 & - \\
$v^{\theta}$ & 0.977 & 0.977 & 0.977 & - \\
$\mathbb{P}$ & 1 & 1 & 1 & 1 \\
$u^{\alpha}$ & 3.947 & 3.966 & 3.974 & 4.000 \\
$u^{\beta}$ & 3.947 & 3.966 & 3.974 & 4.000 \\
$u^{\theta}$ & 2.180 & 2.180 & 2.180 & - \\
\hline & & & & \\
\hline
\end{tabular}

calibrated following the tendencies in data from emerging economies non-performing loans indicators. ${ }^{28}$ Additionally, default penalties for banks are higher than for households, since the volume of credit they trade is higher and at a lower price and they need to be punished more in order to align their incentives.

As a result of our calculation and steady-state FSMLD equilibrium, the profits of banks are about 0.420 per annum. As we have set the amount of lending to 5.294 in steady-state, this means that the annual real profits of the bank are $7.9 \% .{ }^{29}$

\subsection{Steady-state's sensitivity to risk aversion}

Risk aversion plays an important role in the determination of financial fragility. If we assume that there is no risk aversion (i.e., it is equal to zero), then following proposition 4, we would find that default is not related to preferences. Moreover, for risk-neutral agents, default does not depend on their choices. Thus, the risk neutrality becomes - perhaps - too

\footnotetext{
${ }^{28}$ To give an idea of the order of magnitude, we can mention that the average of 14 emerging countries nonperforming loans (IMF Financial Soundness Indicators database) is around 6\% during the first half of 2012. On the other hand, for developed economies, the non-performing loan ratio average (of 14 countries) is between $3 \%-4 \%$.

${ }^{29}$ The average of eight emerging countries' return on assets (the available country data), which is contained in the IMF Financial Soundness Indicators database is around 1.6\% between 2008 and 2011. We have to mention that this discrepancy occurs because our model does not consider the operating costs of the bank.
} 
strong an assumption when analyzing financial fragility issues.

In this section, we develop a sensitivity analysis to investigate the agents' responsiveness to risk aversion. ${ }^{30}$ It is important to notice that this is different from exposing the system to a shock that may affect the equilibrium subject to risk aversion. Instead, it is the assessment of steady-state equilibrium values when varying the risk aversion parameter.

Figure (8) shows the sensitivity of the risk aversion parameter of households. We find that a higher risk aversion is associated with lower repayment rates of households and higher interest rates. This behavior can be explained by proposition 4 , where it can be noted that greater risk aversion increases the marginal utility of defaulting, since agents value marginal consumption relatively more. Additionally, given that repayment rates decline, we have that when the risk aversion of households rises, their credit interest rate increases because of the consequently higher default premium.

The results of varying the risk aversion parameter of banks are shown in figure (9). An increase in risk aversion is associated with greater: i) bank default, ii) supply of loans and iii) household repayment rates, respectively. The first result follows directly from proposition 4 . A greater risk aversion implies an increase in marginal utilities and benefits from defaulting. Thus bank repayment rates are reduced, as in the previous case of households. The second result of the loan supply with respect to risk aversion initially seems to be a counterintuitive outcome when compared to explanations of the financial crisis. For example, Kwan (2010), observed that during the crisis, given the risk aversion of banks, loans were reduced. In contrast, our analysis is different and it is explained by two elements. On the one hand, because the lower repayment implies that the bank has marginally more resources to lend. On the other hand, this is not an analysis of shock effects, instead it is a sensitive exercise of the risk aversion parameter's steady-state equilibrium. Finally, given the second upshot, household credit interest rates decrease and there is cheaper liquidity; hence, more incentives to repay and reduced default.

\subsection{Simulations}

For the dynamic solution of our model, we follow a standard perturbation method procedure. ${ }^{31}$ There are two possible methods for solving the dynamic programming problem of our system. The first is a global method, consisting of solving recursively the Bellman system of equations. This method implies a grid search and consequently the need to specify the special properties of the value function, and it is also computationally demanding. The second is a local method of approximation. Our problem has no severe non-linearities and has a limited number of variables. Therefore, we take the second alternative approach and solve by using a second-order approximation.

In this section we describe the effect of shocks to money, liquidity and fundamentals on Commercial bank interest rate, ${ }^{32}$ inflation, repayment rates, quantities traded, welfare and bank profitability. We compare the effects of shocks in three cases of different liquidity parameterization: i) Basic case with pure cash-in-advance constraint $\left(\bar{\lambda}^{\alpha}=\bar{\lambda}^{\beta}=0\right)$, ii) Asymmetric liquidity case $\left(\bar{\lambda}^{\alpha}=0.5, \bar{\lambda}^{\beta}=0.2\right)$ and iii) Symmetric liquidity case $\left(\bar{\lambda}^{\alpha}=\bar{\lambda}^{\beta}=0.5\right)$. The impulse-response graphs are measured as percentage deviations from the steady-state

\footnotetext{
${ }^{30}$ Recall that the utility function of the households and the bank is CRRA with coefficients of relative risk aversion $\sigma_{h}$ and $\sigma_{\theta}$, respectively. In this subsection the parameters $\sigma_{h}$ and $\sigma_{\theta}$ are between 0.5 and 1.5. For simplicity, we only analyze the case with no market liquidity (i.e., $\lambda^{h}=0$ ).

${ }^{31}$ For further reference, see Sargent (1986), Marimon and Scott (1999) and Sims (2002).

${ }^{32}$ The only financial asset available for both households is credit, which they can obtain from the Commercial bank $\theta$. This asset works exactly as a 1-period maturity bond and it is priced in the commercial loans market. For its pricing, we analyze the interest rate fluctuations, since they provide meaningful and comparable results.
} 
of the selected group of variables. ${ }^{33}$ The time of convergence is measured in quarterly terms.

\section{Funding liquidity}

We shock the monetary base $\left(\Delta^{-} 5 \% \bar{\eta}^{C B}\right)$ as a proxy for changes in funding liquidity, which in turn is transmitted to the rest of the system by two interrelated channels, interest rates and default. The results are presented in figure (10). First, by the credit and REPO market clearing conditions, when the monetary base decreases, interest rates increase in the short run and they adjust to the steady-state level in the long run, as the money base returns to its original value. On the other hand, the second effect is the increase in default incentives because, as we show in proposition 4 , with higher interest rates, it is more attractive to consume than to repay previous debts. ${ }^{34}$ These dynamics determine commodity demand and supply reactions, because of the changes in credit costs and repayments. For instance, the negative monetary shock causes an instantaneous reduction in the demand for commodities that makes inflation drop accordingly. However, in the medium run the increase in defaults and demand for commodities makes inflation grow above its steady-state.

In our setting, agents value trading opportunities. Thus, a negative shock on fiat money is welfare ${ }^{35}$ inferior in the medium run for both households and the Commercial bank. This is because it increases the cost of credit and lowers trade and consumption. Depressed economic scenarios, such that the recent Great Recession, show these characteristics. ${ }^{36}$

\section{Market liquidity}

Market liquidity shocks are proxied by a temporary reduction in the parameter that defines the liquidity of goods $\left(\Delta^{-} 5 \% \lambda^{\alpha}, \Delta^{-} 5 \% \lambda^{\beta}, \Delta^{-} 5 \%\left(\lambda^{\alpha}+\lambda^{\beta}\right)\right)$ and the results are shown in figures (11), (12) and (13). The mechanism by which this component of the model works is the relaxation of budget constraints of households and their effects on the demand for goods and interest rates. If there is a contraction in market liquidity, agents would increase their demand for funding liquidity and interest rates rise accordingly. Additionally, the market liquidity shock by increasing credit costs incentives to consume instead of repaying. Thus, defaults increase and consequently so does financial fragility. As a result, risk premia and interest rates increase accordingly.

Although negative shocks to market and funding liquidity cause a reduction in repayment rates and hence a decrease in welfare, as measured by households' utilities, the liquidity environment is relevant to define the magnitude of responses. On the one hand, figures (10) to (13) show that for funding liquidity shocks the magnitude of responses of financial variables is lower than the one for consumption and utilities. On the other hand, the responses to market liquidity shocks work in the same direction and are all exacerbated by a higher market liquidity parameterization. The first result is explained by the presence of default, since agents optimally decide to smooth the reduction in utility of higher credit costs by

\footnotetext{
${ }^{33}$ Except for the case of inflation, which is measured in percentage terms. All shocks are taken from a normal distribution.

${ }^{34}$ This fact is crucial for financial stability. When the economy is experiencing a bad state of nature, the systemic drivers of the credit market become worse. As a result, there is less agreement on the true value of goods, causing the goods' liquidity to decrease, increasing defaults. We can observe similar issues in the mortgage market during the 2007-2008 crisis. Recall that in this work the liquidity (of goods) is modeled in reduced form as an exogenous shock.

${ }^{35}$ In order to assess welfare, we look at the effects of shocks on the total payoff of households and the commercial bank. These are defined as the utility of consumption or profits minus the associated penalties, respectively.

${ }^{36}$ Since we have incomplete asset markets, and multiple goods, the equilibrium is constrained inefficient. Thus, we make only ordinal comparisons of individual utility and profit functions without attempting to construct an "arbitrary" social welfare function.
} 
decreasing their repayment replacing it with consumption. Meanwhile, the second result is because this channel works primarily through the contraction of budget constraints, and in a higher market liquidity environment, the same shock implies a proportionally higher magnitude of consumption to be reduced together with repayment rates.

\section{Money, liquidity shocks and the Phillips curve}

Our model does not contain any nominal rigidity, as opposed to Calvo (1983) and related literature. However, the interplay of default and liquidity allows us to obtain a version of the Phillips curve, where we relate price variations and trade (as a proxy for output). This is a crucial finding in macroeconomics. That is how figures (4) and (5) illustrate this result. ${ }^{3738}$ We plot trade against inflation in the presence of a positive monetary shock. It shows that in the limiting case where there are no liquidity constraints - or any type of financial friction - trade does not depend on inflation. This in turn is equivalent to the case of fully flexible prices in a Calvo-type model. Finally, it has to be noted that in our case the existence of default results in inflation overshooting, and this is shown in the curve that relates inflation and trade (part with negative slope).
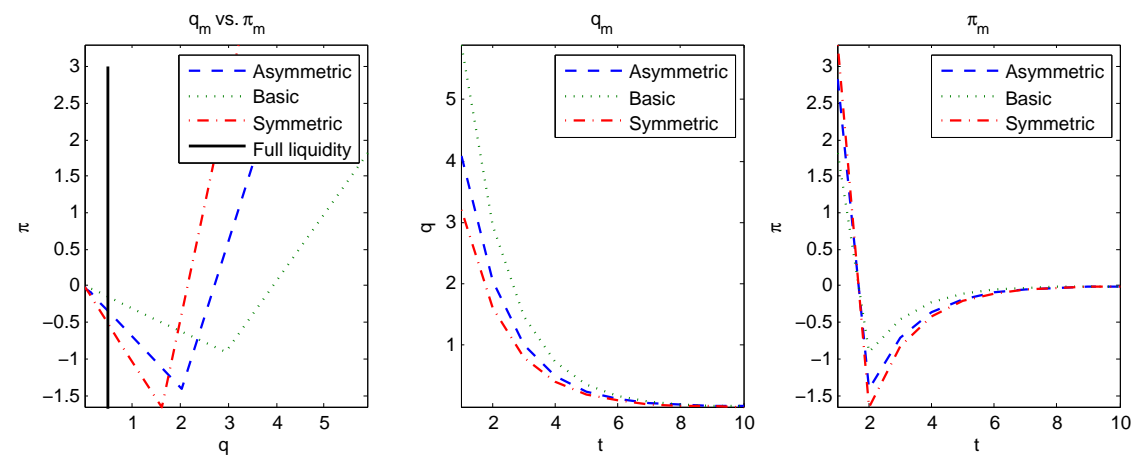

Figure 4: A version of the Phillips curve. Positive monetary shock (5\%)

\section{Fundamentals}

Shocks to endowments $\left(\Delta^{-} 5 \% e^{\alpha}\right)$ approximate changes in fundamental values, similar to the productivity shocks in conventional macro models, although the presented model does not involve a production function. That is how we analyze shocks to agents' endowments in economies with and without default (figure (14)). ${ }^{39}$ In contrast with a defaultable economy, in the economy with full repayment there is no risk premia and rates are equal to zero. In this case, households directly exchange goods to maximize their benefits. Consequently, the presence of banks would not make sense and we would be in a plain Edgeworth economy.

\footnotetext{
${ }^{37}$ The figures show the relationship between inflation $(\pi)$ and aggregate commodity sales $\left(q=q_{1}^{\alpha}+q_{2}^{\beta}\right)$, when subject to a shock in the money base. That is, $\pi_{m}$ vs $q_{m}$

${ }^{38}$ As we have not formally introduced monetary policy via a Taylor rule, we refrain from analyzing the trade off between financial and price stability. However, this very important issue merits further consideration in future work. We are grateful to an anonymous referee for bringing our attention to this important point.

${ }^{39}$ We also plot the effects of an aggregate shock to endowments. In this case, in an Edgeworth economy, as there is full flexibility of prices, welfare is not altered. However, in a defaultable economy, as there are costs associated to financing, the flexibility of goods' prices is lower. Thus there are effects in welfare, as quantities and aggregate prices react at different speeds.
} 

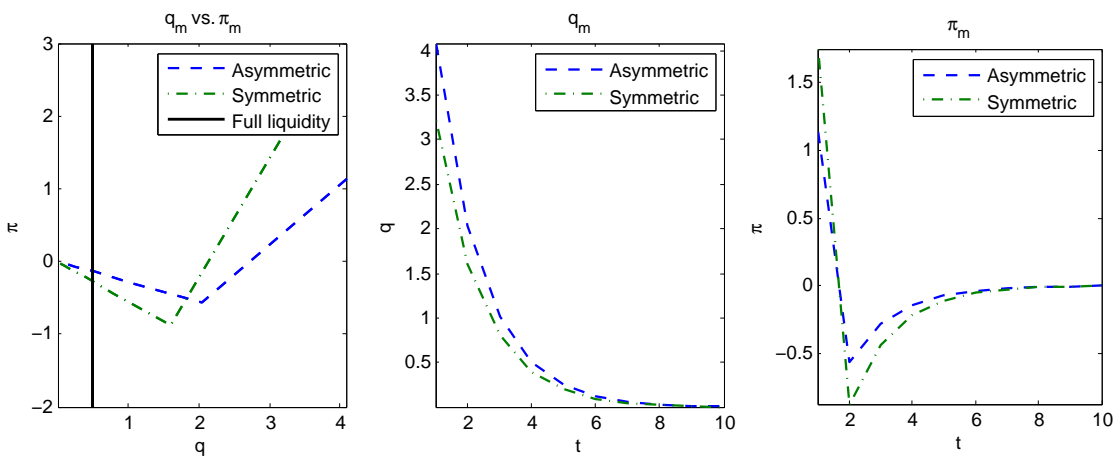

Figure 5: A version of the Phillips curve. Positive market liquidity shock (5\%)

Under these conditions, a shock to a particular agent's endowment produces a change in relative prices only. On the other hand, in a defaultable economy the adjustment comes through both prices and interest rates. In the latter case, a change in interest rates dampens the reaction of prices. As a result, in the economy with full repayment there is higher price flexibility and the relative scarcity in the commodities' market produces a larger increase in inflation. ${ }^{40}$

Additionally, a negative shock to a particular agent's endowment increases the marginal utility of the good the agent is endowed with. The impact will be different depending on whether the economy admits default (see equations (47) and (48)). The reaction of marginal utility is higher in an economy without default, given that the possibility of defaulting allows agents to consume relatively more at the margin. As a result, trade response is higher in a defaultable economy and the household's liquidity constraints work as a "financial accelerator." That is, as in Bernanke et al. (1999), endogenous developments in financial markets work to propagate and amplify the effect of shocks to the economy. Furthermore, the existence of higher trade in goods increases the speed of adjustment of the households' utility to its steady-state level. ${ }^{41}$

\subsection{Financial stability analysis}

One of the advantages of our model is that it allows us to assess the effects of shocks to financial fragility (or absence of stability $)^{42}$. In this subsection we describe financial stability results in the presence of default and liquidity. As we have seen in the previous sections and according to Goodhart et al. (2006), financial stability can be roughly approximated by bank profitability and repayment rates. If banks suffer some unexpected shock that increases their default probability, they are able to use their own equity to overcome potential losses. However, if a bank does not have resources, then it may default, affecting other institutions by direct (e.g. by financial linkages) and indirect channels (e.g. common factors exposure).

\footnotetext{
${ }^{40}$ Based on the analysis of the average frequencies of price changes, using micro data, many studies find evidence of the existence of price rigidities (see the discussion in Gali (2008)). In this sense, in a model of staggered price adjustment, output movements have a higher impact on current inflation when the average time between price changes for an individual firm decreases (Calvo (1983), and Walsh (2010)). In contrast, instead of using price rigidities, in our model the same effect is uncovered through default and liquidity constraints.

${ }^{41}$ Nevertheless, it should be noted that, if the assets market is incomplete, a competitive equilibrium is not efficient (see Geneakoplos (1990), and Rios-Rull (1994)). This is observed in steady-state values of households' utilities, where lower liquidity constraints (i.e. more completeness) imply higher magnitudes.

${ }^{42}$ There have been various empirical attempts to estimate magnitudes of potential financial turbulence on the financial markets. For a recent application to emerging markets that incorporates the banking system, as network, see Martinez-Jaramillo et al. (2010).
} 
Through the comparison of different impulse responses we can rank the impact of shocks, assess the relative importance of financial stability and price stability, and measure the magnitude of the effects on the real economy.

\section{Market liquidity and default}

The response to contractionary market liquidity shocks across agents is analyzed here. Market liquidity in our setting works through the budget constraints relaxation parameter. Thus, it defines the financing opportunities of agents. In this sense, higher market liquidity is associated with lower credit demand, and lower financial frictions.

Among other things, our results show that a negative market liquidity shock has mixed effects on financial stability. On the one hand, the repayment rate of households and the bank's profitability decrease in the medium run and converge to the their steady-state levels in the long run. However, on the other hand, we observe that the repayment rate of banks increases in the short run. First, the relative excess of borrowing needs, caused by the lack of market liquidity, brings lower households' repayment rates due to higher financing costs, as before (recall proposition 4). This causes banking profits to decrease. Conversely, as mentioned, the banking utility improves in the short run, it overshoots to worsen in the medium run and then converges (from below) to its steady-state level. The explanation of this dynamic can be found in proposition 4. Equation (34) shows the equilibrium condition for default of the Commercial bank. The key component is inflation. Unlike of households' repayment and interest rates, this variable overshoots in the medium run. As we explained in the previous section, a negative shock of market liquidity causes prices to decrease sharply in the short run. This increases the bank's marginal cost of defaulting and improves its immediate repayment. Consequently, the bank lowers its default punishment and improves its utility. However, as prices overshoot in the medium run, they decrease the marginal cost of defaulting and the bank's delivery and utility overshoots below to the steady-state level.

Additionally, traded quantities $\left(q^{h}\right)$ and households' utilities $\left(U^{h}\right)$ plots in Figures (11) to (11) show that the response of welfare comes later than the one in trade and it is aligned to the decay in repayments that occurs first. This evidence suggests that trade can be considered as an early warning indicator of financial stability and economic performance.

\section{Funding liquidity, financial and price stability}

In this section we describe the responses of the system to monetary - or funding liquidity shocks. Our results suggest that the performance of the Commercial bank is more sensitive to funding than to market liquidity perturbations.

The simulations results indicate that financial stability is relatively more affected than price stability in the presence of a monetary shock. In the short run, inflation responds to the negative shock to the monetary base by decreasing its level. However, in the medium run, inflation as well as repayment rates revert their patterns. As we can observe in Figure (6), in this framework, yet reduced through our initial parameterization, monetary policy needs to incorporate financial stability, because trying to improve price stability can generate financial distress and a detriment to trade and welfare.

Additionally, albeit reducing inflation in the short run, a sudden contractionary monetary policy causes a reduction in repayments and simultaneous inflation growth in the medium run. As explained before, this counterintuitive result is obtained because a shock to the monetary base affects simultaneously demand and supply of traded goods. When the supply of goods is more sensitive to an increase in interest rates, as in our case, it is possible to observe a temporary rise in inflation. Therefore, regulators should consider not only the 
effects of monetary policy on the demand, but also the supply side of the economy.
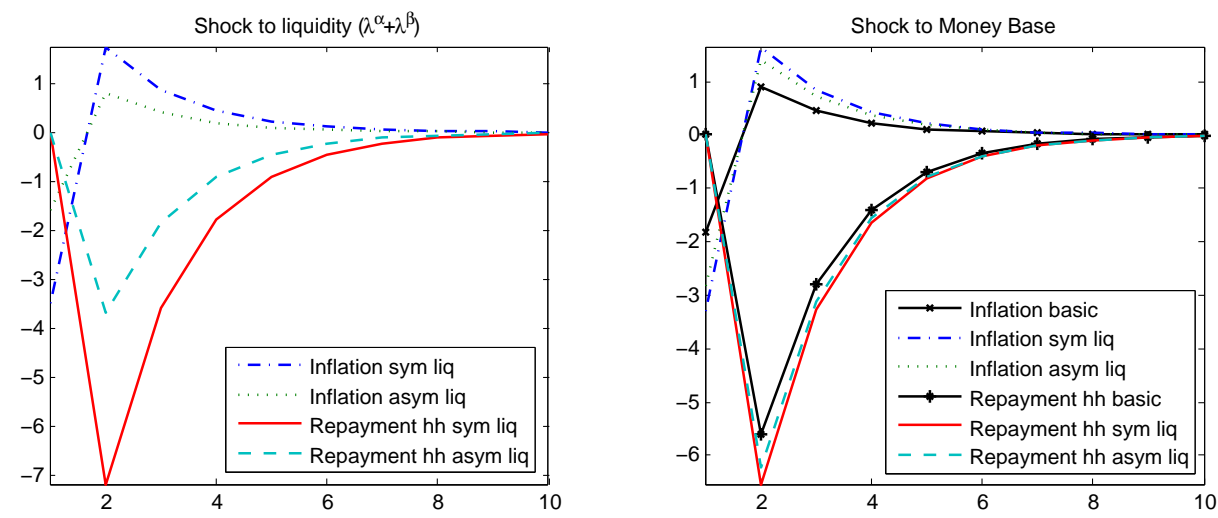

Figure 6: Simulation plot, $\Delta^{-} 5 \% \lambda^{\alpha}+\lambda^{\beta}, \Delta^{-} 5 \%$ M. Repayment rate is in percentage variations with respect to steady-state levels and inflation is the gross rate.

As in the case of a negative shock to market liquidity, in the funding liquidity shock responses, welfare lags trade. When interest rates are low, a reduction in the monetary base decreases trade by a higher extent than the benefits obtained from price control. Therefore, as the empirical literature suggests, there is a trade-off between price stability and welfare. However, we have to note that since we model neither production nor nominal frictions, all the other welfare effects are determined through trade.

An additional illustration of trade - hence welfare - effects of the previous crisis can be found in figure (7). ${ }^{43}$ As we can observe, after approximately one year of the liquidity dry-up at the second quarter of 2007, real effects of the financial crisis started to appear and global trade was significantly reduced. As we previously mentioned, we obtain a similar result in our trade and utility simulations after a negative liquidity shock: a funding liquidity (monetary base) shock and/or a market (goods') liquidity shock. ${ }^{44}$

We hasten to add that the rigorous study of macroprudential regulation and its interaction with monetary policy needs further consideration. Given the functions of liquidity provision, monitoring, and risk sharing of the banking sector, we would need to analyze the optimal regulatory mix along the lines of Kashyap et al. (2014). In particular it is relevant to assess the role of capital and liquidity requirements, net stable funding ratios (NSFRs) and countercyclical buffers. However, given the simplifications made in this paper, to introduce and explain the framework and its mechanisms, we leave these important features for future research.

\footnotetext{
${ }^{43}$ The emerging and developing countries that we have considered (the IMF definition) are those with available data.

${ }^{44}$ However, after 2010 , we see that trade reduction coincides with the market liquidity set-back. This observation suggests a more compressed economic situation and poses additional elements to our analysis. These will be addressed in future works.
} 


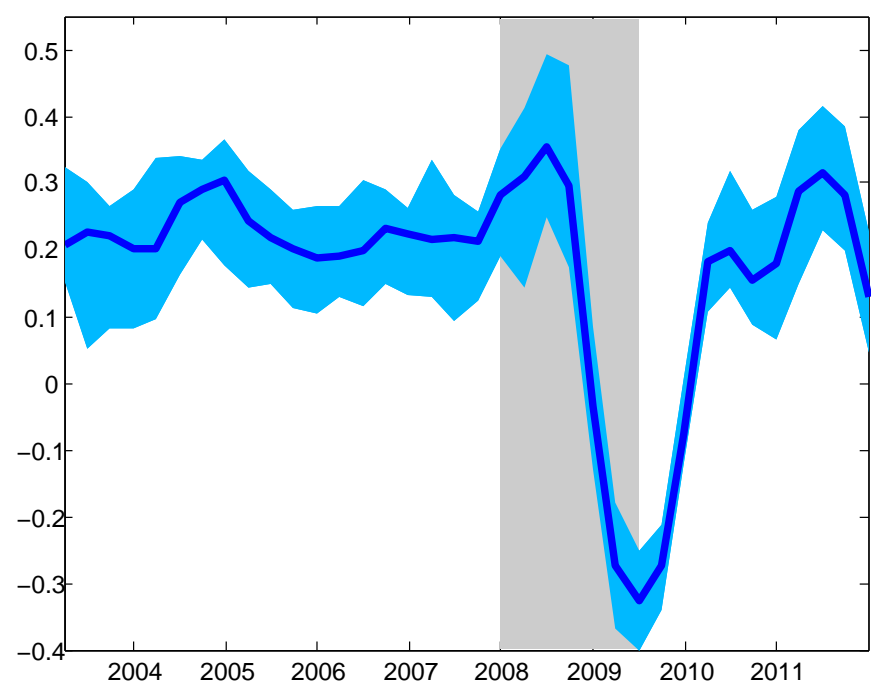

Figure 7: Exports plus imports yearly changes on quarterly nominal data in US dollars for emerging and developing countries. Source: IFS database, International Monetary Fund. Shaded sky blue zone represents first and third quartile, solid line is the median. Shaded gray zone represents NBER's Business Cycle date for Great Recession.

\section{Concluding Remarks}

We have developed a model that, by including agent heterogeneity, liquidity and endogenous default in a pure exchange DSGE model, is capable of addressing issues of financial stability and appropriate policy responses.

Our results suggest that liquidity and default in equilibrium should be studied contemporaneously due to their interconnectedness and welfare effects. Moreover, agent heterogeneity is essential for assessing the distributional effects of exogenous shocks, since these depend primarily on the part of the economy directly affected. In addition, the presence of financial frictions underlines the importance of studying the impact of shocks to the short as well as the medium-run behavior of financial variables and welfare.

Unlike New-Keynesian models, due to endogenous determination of interest rates and default in the credit market, there is no need to resort to artificial fixing of prices - that violates market clearing - to obtain equilibria characterized by real as well as nominal determinacy. Thus, we are able to derive a relationship between prices and trade, akin to the Phillips curve, with the inclusion of default but without further nominal frictions.

More importantly, credit spreads are endogenously determined and indicative of financial distress as they incorporate the default and liquidity premia as well. Finally, market incompleteness and the role of aggregate uncertainty are captured by the fact that not all risks can be hedged with the existing financial assets.

Following the results of our study, we propose two further developments in this framework. First, microfoundations of liquidity of financial assets and their interconnectedness with the liquidity of goods are warranted. Second, consideration of liquidity in the measurement of financial stability, as we establish in this work, is necessary when addressing financial fragility.

Our model is also capable of estimating the aggregate velocity in an economy. In particular, in principle, one can potentially estimate the liquidity parameters from real data, thus gen- 
erating a disaggregate measure of velocity. Therefore, by considering "individual market" liquidity, one can derive micro-founded measures of aggregate velocity in the economy and estimate precisely its composition. 


\section{References}

Acharya V. and L. Pedersen, Asset Pricing with Liquidity Risk; Journal of Financial Economics, 77, 375-410, 2005.

Acharya V. and Richardson, Matthew P., Causes of the Financial Crisis; Critical Review, Vol. 21, Nos. 2, 3, pp. 195-210, 2009.

Adrian T., Shin H.S., Financial Intermediaries and Monetary Economics; Handbook of Monetary Economics (eds.) Benjamin Friedman and Michael Woodford, Elsevier, chapter 12, 601-650, 2011.

Adrian T., Shin H.S., Liquidity and Leverage; Journal of Financial Intermediation, 19 (3), 418-437, 2010.

Adrian, T., Shin H.S., Money, Liquidity and Monetary Policy; American Economic Review (papers and proceedings), 99, 600-605, 2009.

Arora V. B. and Cerisola, Martin D. D., How Does U.S Monetary Policy Influence Economic Conditions in Emerging Markets?; IMF Working Paper, Vol. , pp. 1-28, 2000.

Basel Comittee on Banking Supervision. Basel III: A global regulatory framework for more resilient banks and banking systems; Basel: Bank for International Settlements, 2011.

Bernanke B., Gertler, M., Gilchrist, S. The Financial Accelerator in a Quantitative Business Cycle Framework, Handbook of Macroeconomics, in: J. B. Taylor \& M. Woodford ed., Handbook of Macroeconomics, edition 1, volume 1, chapter 21, pages 1341-1393 Elsevier, 1999.

Brunnermeier M., L. Pedersen, Market Liquidity and Funding Liquidity; Review of Financial Studies, 22(6), 2201-2238, 2009.

Calvo G. Staggered prices in a utility maximizing framework, Journal of Monetary Economics 12, 383-398, 1983.

Christiano L., Eichenbaum M. and Evans C. Modeling Money, NBER Working Papers 6371, National Bureau of Economic Research, 1998.

Cole H., Discussion of Gertler and Karadi: A model of unconventional monetary policy, Journal of Monetary Economics, 58(1), pp 35-38, 2011.

Covas F. and Shigeru Fujita. Procyclicality of Capital Requirements in a General Equilibrium Model of Liquidity Dependence, International Journal of Central Banking, vol. 6(34), pages 137-173, , 2010.

de Walque, G., O. Pierrard y A. Rouabah, Financial (in)stability, supervision, and liquidity injections: a dynamic general equilibrium approach; Economic Journal, 120(549):1234-1261, 2010.

Dubey P., Geanakoplos J. and Shubik M., Default and Punishment in General Equilibrium; Econometrica, 73(1):1-37, 2005.

Dubey P., John Geanakoplos, Monetary Equilibrium with Missing Markets; Journal of Mathematical Economics, 39: 585-618. [CFDP 1389 and CFP 1063], 2003. 
Espinoza R., CAE Goodhart and D. P. Tsomocos State prices, liquidity and default, Economic Theory, Springer, vol. 39(2), pages 177-194, 2009.

Espinoza R., Dimitrios P. Tsomocos Monetary Transaction Costs and the Term Premium; Economic Theory, forthcoming, 2015e.

Fisher I., The Purchasing Power of Money: Its Determination and Relation to Credit, Interest, and Crises; Library of Economics and Liberty; (LE\&L),1911a.

Fostel A. and John Geanakoplos, Leverage Cycles and the Anxious Economy; American Economic Review, 98(4): 1211-1244, 2009.

Gali J. Monetary Policy, Inflation, and the Business Cycle: An Introduction to the New Keynesian Framework, Princeton University Press, 2008.

Gertler M. and Karadi, P. A model of unconventional monetary policy. Journal of Monetary Economics, 58(1):285-335, 2011.

Goodhart C. A. E. with Sunirand, P. and Tsomocos, D., A model to analyse financial fragility; Economic Theory, 27, pp. 107-142, 2006.

Grandmont J.M and Y. Younes, On the Role of Money and the Existence of a Monetary Equilibrium, Review of Economic Studies, Vol. 39, pp. 355-372, 1972.

Gromb D. and Dimitri Vayanos,Equilibrium and Welfare in Markets with Financially Constrained Arbitrageurs, Journal of Financial Economics, Vol. 66, pp. 361-407, 2002.

Hart O. and John Moore, Incomplete Contracts and Renegotiation, Econometrica, Vol. 56, No. 4, pp. 755-785, 1988.

Iacoviello, M. and S. Neri, Housing Markets Spillovers: Evidence from an Estimated DSGE Model; American Economic Journal: Macroeconomics, American Economic Association, vol. 2(2), pages 125-64, April, 2010.

Kashyap A. K., Dimitrios Tsomocos and Alexandros Vardoulakis, Principles for Macroprudential Regulation, Banque de France Financial Stability Review, No. 18, pp. 173-182, 2014.

King R. and Rebelo, S. Resuscitating real business cycles, Handbook of Macroeconomics, edition 1, volume 1, chapter 14, pages 927-1007, 1999.

Kiyotaki N. and John Moore, Liquidity, Business Cycles, and Monetary Policy, Clarendon Lectures LSE, 2001. Latest version, NBER Working Papers 17934, National Bureau of Economic Research, 2012.

Leao E., and P. Leao, Modelling the central bank repo rate in a dynamic general equilibrium framework, 2007; Economic Modelling,24, pp. 571-610, 2006.

Lin L., Dimitrios Tsomocos and Alexandros Vardoulakis, Debt Deflation Effects of Monetary Policy, Finance and Economics Discussion Series 2014-37, Board of Governors of the Federal Reserve System (U.S.), 2014.

Marimon R. and Scott, A., (eds.) Computational Methods for the Study of Dynamic Economies, Oxford University Press, Oxford, UK, 1999.

Martinez-Jaramillo S., Omar Perez Perez, Fernando Avila Embriz and Fabrizio Lopez Gallo Dey, Systemic risk, financial contagion and financial fragility; Journal of Economic Dynam- 
ics and Control, Volume 34, Issue 11, 2358-2374, 2011.

Martinez, J.F. and Andrew Powell On Emerging Economy Sovereign Spreads and Ratings, Inter American Development Bank, Working Paper 629, 2008.

Meh C.A. and Moran, Kevin. The role of bank capital in the propagation of shocks, Journal of Economic Dynamics and Control, Elsevier, vol. 34(3), pages 555-576, 2010.

Sargent T., Dynamic Macroeconomic Theory, Harvard University Press , Cambridge, Ma, 1986.

Sims C. A., Solving Linear Rational Expectations Models, Computational Economics, 20,1$20,2002$.

Shubik M., Charles Wilson, The Optimal Bankruptcy Rule in a Trading Economy Using Fiat Money; Zeitschrift fur Nationalokonomie, 37, 3-4, 337-354, CFP 465, 1977.

Shubik M., The Theory of Money and Financial Institutions; Cambridge, MA; UK: MIT Press, 1999.

Stein J., Monetary policy as financial stability regulation; The Quarterly Journal of Economics, 127(1), 57-95, 2012.

Tsomocos D., Equilibrium Analysis, Banking, and Financial Instability; Journal of Mathematical Economics, 39 (5-6), 619-655, 2003.

Vayanos D., Flight to Quality, Flight to Liquidity and the Pricing of Risk; working paper, London School of Economics, 2004.

Walsh C. Monetary Theory and Policy, Third ed., MIT Press, 2010. 


\section{Appendix 1: Inflation index derivation}

In order to define inflation in terms of the model variables, we need to determine a price index for $P_{t}$, which should be a weighted average of products of the representative consumption basket in the economy. As we only have two goods, we can use these goods weights in order to build the basket. Therefore we have:

$$
P_{t}=\omega_{1}^{p} p_{1, t}+\omega_{2}^{p} p_{2, t}
$$

Where $\omega_{1}^{p}$ and $\omega_{2}^{p}$ are the weights of the goods in the consumption basket, and $p_{1, t}$ and $p_{2, t}$ are the prices of the goods 1 and 2 , respectively.

In practice, the index is calculated by considering a fixed basket at the baseline year. The common trend analyzed by Roberts (2000) in the historic context, is to use a Laspeyres $(1864,1871,1883)$ type of index, which in our two goods case is defined as follows.

$$
P_{t}=\frac{p_{1, t} q_{1,0}^{\alpha}+p_{2, t} q_{2,0}^{\beta}}{p_{1,0} q_{1,0}^{\alpha}+p_{2,0} q_{2,0}^{\beta}}
$$

Where $q_{1,0}^{\alpha}$ and $q_{2,0}^{\beta}$ are the commodities quantities traded by the households at the baseline year time period (i.e. $\mathrm{t}=0$ ). In our case, we are using year zero as our basis. As we start from the steady-state, all the variables at time zero are the steady-state variables. Therefore, we have the following equation for the price index.

$$
P_{t}=\frac{p_{1, t} \bar{q}_{1}^{\alpha}+p_{2, t} \bar{q}_{2}^{\beta}}{\bar{p}_{1} \bar{q}_{1}^{\alpha}+\bar{p}_{2} \bar{q}_{2}^{\beta}}
$$

Where $\bar{q}_{1}^{\alpha}$ and $\bar{q}_{2}^{\beta}$ correspond to the commodities quantities traded by the households at the steady-state. As we see in the previous index, a convenient selection of weights allows us to investigate some interesting features of our model. The weights are determined to meet three requirements. First, we need the weights to add up to one. Second, we need the weights to allow us to construct the inflation as a function of the variables of our model. Third, we need to be able to derive the quantity theory of money proposition.

If we conveniently calculate our index in terms of changes with respect to the baseline year, the equation (40) becomes.

$$
P_{t}=\omega_{1}^{p} \frac{p_{1, t}}{\bar{p}_{1}}+\omega_{2}^{p} \frac{p_{2, t}}{\bar{p}_{2}}
$$

Therefore, in order for the relationship in equation (40) to hold, we need to define the following weights.

$$
\begin{aligned}
& \omega_{1}^{p}=\frac{\bar{p}_{1} \bar{q}_{1}^{\alpha}}{\bar{p}_{1} \bar{q}_{1}^{\alpha}+\bar{p}_{2} \bar{q}_{2}^{\beta}} \\
& \omega_{2}^{p}=\frac{\bar{p}_{2} \bar{q}_{2}^{\beta}}{\bar{p}_{1} \bar{q}_{1}^{\alpha}+\bar{p}_{2} \bar{q}_{2}^{\beta}}
\end{aligned}
$$

As we can observe, the weights add up to one. By replacing this definition of weights in the expression for inflation, we have.

$$
\mathbb{P}_{t}=\left(1+\pi_{t}\right)=\frac{p_{1, t} \bar{q}_{1}^{\alpha}+p_{2, t} \bar{q}_{2}^{\beta}}{p_{1, t-1} \bar{q}_{1}^{\alpha}+p_{2, t-1} \bar{q}_{2}^{\beta}}
$$




\section{Appendix 2: Model details}

Decision variables

$$
\begin{aligned}
& \Sigma^{\alpha}=\left\{\mu_{t}^{\alpha}, b_{2, t}^{\alpha}, v_{t}^{\alpha}, q_{1, t}^{\alpha}\right\}_{t=0}^{\infty} \\
& \Sigma^{\beta}=\left\{\mu_{t}^{\beta}, b_{1, t}^{\beta}, v_{t}^{\beta}, q_{2, t}^{\beta}\right\}_{t=0}^{\infty} \\
& \Sigma^{\theta}=\left\{\Pi_{t}^{\theta}, \mu_{t}^{\theta}, l_{t}^{\theta}, v_{t}^{\theta},\right\}_{t=0}^{\infty}
\end{aligned}
$$

Macroeconomic variables

$$
\kappa=\left\{M_{t}, \mathbb{P}_{t}, r_{t}^{c}, r_{t}^{I B}, R_{t}, \tau^{\alpha}, \tau^{\beta}, \tau^{\theta}, \lambda_{t}^{\alpha}, \lambda_{t}^{\beta}\right\}_{t=0}^{\infty}
$$

\section{Parameters}

$$
\delta=\left(\bar{\eta}^{C B}, \bar{\lambda}^{\alpha}, \bar{\lambda}^{\beta}, \bar{\lambda}^{\theta}, \bar{e}_{1}^{\alpha}, \bar{e}_{2}^{\beta}, \beta, \hat{\beta}, \rho^{C B}, \rho_{e}^{\alpha}, \rho_{e}^{\beta}, \bar{M}, \phi\right)
$$

Budget sets

$$
\begin{gathered}
B^{\alpha}(\kappa)=\left\{\Sigma^{\alpha}:(1 \alpha)-(2 \alpha) \text { hold }\right\} \\
B^{\beta}(\kappa)=\left\{\Sigma^{\beta}:(1 \beta)-(2 \beta) \text { hold }\right\} \\
B^{\theta}(\kappa)=\left\{\Sigma^{\theta}:(3)-(5) \text { hold }\right\}
\end{gathered}
$$

\section{Endogenous variables}

$$
\left\{p_{1, t}, p_{2, t}, \mathbb{P}_{t}, r_{t}^{c}, r_{t}^{I B}, R_{t}, \mu_{t}^{\alpha}, b_{2, t}^{\alpha}, v_{t}^{\alpha}, q_{1, t}^{\alpha}, \eta_{1, t}^{\alpha}, \eta_{2, t}^{\alpha}, \mu_{t}^{\beta}, b_{1, t}^{\beta}, v_{t}^{\beta}, q_{2, t}^{\beta}, \eta_{1, t}^{\beta}, \eta_{2, t}^{\beta}, \Pi_{t}^{\theta}, \mu_{t}^{\theta}, l_{t}^{\theta}, v_{t}^{\theta}, \eta_{1, t}^{\theta}, \eta_{2, t}^{\theta}\right\}_{t=0}^{\infty}
$$

Variables being shocked

$$
\varphi=\left\{M_{t}, \lambda_{t}^{\alpha}, \lambda_{t}^{\beta}, e_{1, t}^{\alpha}, e_{2, t}^{\beta}\right\}_{t=0}^{\infty}
$$

\section{Appendix 3: Proof of the propositions}

\subsection{Proposition 1: Money non-neutrality}

\section{Proof}

From the FOC (59) and (60) for agent $\alpha$, we have:

$$
\frac{\partial u\left(c_{1, t}^{\alpha}, c_{2, t}^{\alpha}\right)}{\partial c_{1, t}^{\alpha}}-\frac{\partial u\left(c_{1, t}^{\alpha}, c_{2, t}^{\alpha}\right)}{\partial c_{2, t}^{\alpha}} \frac{p_{1, t}}{p_{2, t}} \lambda_{t}^{\alpha}=p_{1, t} \beta \mathbb{E}_{t}\left(\frac{\tau_{t+1}^{\alpha}}{\mathbb{P}_{t+1}}\right)\left(1-\lambda_{t}^{\alpha}\right)
$$

Combining with (57) and (58), we have that:

$$
\frac{\partial u\left(c_{1, t}^{\alpha}, c_{2, t}^{\alpha}\right)}{\partial c_{1, t}^{\alpha}}-\frac{\partial u\left(c_{1, t}^{\alpha}, c_{2, t}^{\alpha}\right)}{\partial c_{2, t}^{\alpha}} \frac{p_{1, t}}{p_{2, t}} \lambda_{t}^{\alpha}=\frac{1}{1+r_{t}^{c}} \frac{\partial u\left(c_{1, t}^{\alpha}, c_{2, t}^{\alpha}\right)}{\partial c_{2, t}^{\alpha}} \frac{p_{1, t}}{p_{2, t}}\left(1-\lambda_{t}^{\alpha}\right)
$$

And simplifying, we have,

$$
\frac{\partial u\left(c_{1, t}^{\alpha}, c_{2, t}^{\alpha}\right)}{\partial c_{1, t}^{\alpha}}=\frac{\partial u\left(c_{1, t}^{\alpha}, c_{2, t}^{\alpha}\right)}{\partial c_{2, t}^{\alpha}} \frac{p_{1, t}}{p_{2, t}}\left(\frac{1+\lambda_{t}^{\alpha} r_{t}^{c}}{1+r_{t}^{c}}\right)
$$

Similarly, for household $\beta$, we have:

$$
\frac{\partial u\left(c_{1, t}^{\beta}, c_{2, t}^{\beta}\right)}{\partial c_{2, t}^{\beta}}=\frac{\partial u\left(c_{1, t}^{\beta}, c_{2, t}^{\beta}\right)}{\partial c_{1, t}^{\beta}} \frac{p_{2, t}}{p_{1, t}}\left(\frac{1+\lambda_{t}^{\beta} r_{t}^{c}}{1+r_{t}^{c}}\right)
$$


Suppose that at some period $t, M_{t}$ decreases. From REPO market clearing condition (17) we have that it translates into an increase of $r_{t}^{I B}$, and if budget conditions are binding, $r_{c}$ decreases accordingly. If we also have that $\lambda_{t}^{\alpha}$ is decreasing (or constant), for (47) to hold, $p_{1, t} / p_{2, t}$ must increase. Whereas, for (48) to hold, if $\lambda_{t}^{\alpha}$ is decreasing (or constant), $p_{2, t} / p_{1, t}$ must increase. This is a contradiction. Therefore, monetary policy is not neutral in the short-run if $\lambda^{\alpha}, \lambda^{\beta} \in[0,1)$. The consequent inequality in quantities after a change in OMOs is guaranteed by our logarithmic utility functions.

\subsection{Proposition 2: Fisher effect}

\section{Proof.}

It follows directly from the Money-non neutrality proposition proof, equations (47) and (48) above.

\subsection{Proposition 3: Quantity theory of money}

\section{Proof.}

In an interior equilibrium and with no money carried over, all the budget constraints are binding. We add budget constraints $(2 \mathrm{a})$ and $(2 \mathrm{~b})$, and we have:

$$
b_{2, t}^{\alpha}+b_{1, t}^{\beta} \leq \lambda_{t}^{\alpha} \cdot p_{1, t} q_{1, t}^{\alpha}+\lambda_{t}^{\beta} \cdot p_{2, t} q_{2, t}^{\beta}+\frac{\mu_{t}^{\alpha}}{1+r_{t}^{c}}+\frac{\mu_{t}^{\beta}}{1+r_{t}^{c}}
$$

From the goods market clearing condition (15) and the previous relation, we have:

$$
p_{1, t} q_{1, t}^{\alpha}+p_{2, t} q_{2, t}^{\beta} \leq \lambda_{t}^{\alpha} \cdot p_{1, t} q_{1, t}^{\alpha}+\lambda_{t}^{\beta} \cdot p_{2, t} q_{2, t}^{\beta}+\frac{\mu_{t}^{\alpha}}{1+r_{t}^{c}}+\frac{\mu_{t}^{\beta}}{1+r_{t}^{c}}
$$

Finally, by the Consumer Loans and REPO market-clearing conditions (16) and (17), respectively, we have:

$$
p_{1, t} q_{1, t}^{\alpha}+p_{2, t} q_{2, t}^{\beta}=\lambda_{t}^{\alpha} \cdot p_{1, t} q_{1, t}^{\alpha}+\lambda_{t}^{\beta} \cdot p_{2, t} q_{2, t}^{\beta}+M_{t}
$$

Where the equality comes from the assumption of no money being carried over, so the market clearing conditions are binding. Rearranging we have that relation (23) holds.

\subsection{Proposition 4: On the verge condition}

\section{Proof}

The proof follows immediately from agents $\alpha$ and $\beta$ and bank $\theta$ FOCs.

\subsection{Proposition 5: Interest rates under default and no default, case of the households}

\section{Proof}

From agents $\alpha$ and $\beta$ 's budget constraints (1a) and (1b) sum, and the assumption that no money is carried over (i.e. budget constraints are binding), we have:

$$
v_{t}^{\alpha} \mu_{t-1}^{\alpha}+v_{t}^{\beta} \mu_{t-1}^{\beta}=p_{1, t-1} q_{1, t-1}^{\alpha}\left(1-\lambda_{t-1}^{\alpha}\right)+p_{2, t-1} q_{2, t-1}^{\beta}\left(1-\lambda_{t-1}^{\beta}\right)
$$

From agents $\alpha$ and $\beta$ 's budget constraints (2a) and (2b) sum, and the same previous assumption, we have:

$$
b_{2, t}^{\alpha}+b_{1, t}^{\beta}=\lambda_{t}^{\alpha} p_{1, t} q_{1, t}^{\alpha}+\lambda_{t}^{\beta} p_{2, t} q_{2, t}^{\beta}+\frac{\mu_{t}^{\alpha}+\mu_{t}^{\beta}}{1+r_{t}^{c}}+(1-\phi) \Pi_{t}^{\theta}
$$


Additionally, from the market clearing conditions (14) and (15) addition we have:

$$
b_{1, t}^{\beta}+b_{2, t}^{\alpha}=p_{1, t} q_{1, t}^{\alpha}+p_{2, t} q_{2, t}^{\beta}
$$

Finally, from equations (52), (53) and (54) we have that the following relation must hold,

$$
\mathbb{E}_{t}\left(R_{t+1}\right)=\frac{1}{1+r_{t}^{c}}+\frac{(1-\phi) \Pi_{t}^{\theta}}{\mu_{t}^{\alpha}+\mu_{t}^{\beta}}
$$

In the full delivery case, ${ }^{45}$ we have that $v_{t}^{\alpha}=v_{t}^{\beta}=1$. Thus, in equation (55) we have $\mathbb{E}_{t}\left(R_{t+1}\right)=1, \Pi_{t}^{\theta}=0$ and it must be the case that $r_{t}^{c}=0$. Whereas for the case where $v_{t}^{\alpha}<1$ or $v_{t}^{\beta}<1$ or both, $r_{t-1}^{c}$ must be strictly greater than zero. This applies $\forall t \in T$.

\subsection{Proposition 6: Interest rates under default and no default, case of the bank}

\section{Proof}

In the case of bank $\theta$, from the combination of $\mathrm{FOC}$, we can easily derive that:

$$
\mathbb{E}_{t}\left(R_{t+1}\right)=\left(\frac{1+r_{t}^{I B}}{1+r_{t}^{c}}\right)
$$

Therefore, in the full delivery case (in $t+1$ ), we need that $r_{t}^{c}=r_{t}^{I B}=0$. Meanwhile, in the case of partial default $\left(\mathbb{E}_{t}\left(R_{t+1}\right)<1\right)$, we must have that $0<r_{t}^{I B}<r_{t}^{c}$. $\square$

\footnotetext{
${ }^{45}$ Recall that $v_{t}^{\alpha}, v_{t}^{\beta} \in[0,1]$.
} 


\section{Appendix 4: First Order Conditions}

10.1 FOCs for Household $\alpha$

$$
\begin{aligned}
-\frac{\eta_{2, t}^{\alpha}}{1+r_{t}^{c}}-\beta \mathbb{E}_{t}\left(\frac{\tau^{\alpha}\left(1-v_{t+1}^{\alpha}\right)}{\mathbb{P}_{t+1}}-\eta_{1, t+1}^{\alpha} v_{t+1}^{\alpha}\right) & =0 \\
\frac{\tau^{\alpha}}{\mathbb{P}_{t}}+\eta_{1, t}^{\alpha} & =0 \\
\frac{1}{b_{2, t}^{\alpha}}+\eta_{2, t}^{\alpha} & =0 \\
\frac{1}{e_{1, t}^{\alpha}-q_{1, t}^{\alpha}}+\eta_{2, t}^{\alpha} \lambda_{t}^{\alpha} p_{1, t}+\beta \mathbb{E}_{t}\left(\eta_{1, t+1}^{\alpha} p_{1, t}\left(1-\lambda_{t}^{\alpha}\right)\right) & =0 \\
v_{t}^{\alpha} \mu_{t-1}^{\alpha}-p_{1, t-1} q_{1, t-1}^{\alpha}\left(1-\lambda_{t-1}^{\alpha}\right) & =0 \\
b_{2, t}^{\alpha}-\frac{\mu_{t}^{\alpha}}{1+r_{t}^{c}}-\lambda_{t}^{\alpha} p_{1, t} q_{1, t}-\frac{1-\phi}{2} \Pi_{t}^{\theta} & =0
\end{aligned}
$$

10.2 FOCs for Household $\beta$

$$
\begin{aligned}
-\frac{\eta_{2, t}^{\beta}}{1+r_{t}^{c}}-\beta \mathbb{E}_{t}\left(\frac{\tau^{\beta}\left(1-v_{t+1}^{\beta}\right)}{\mathbb{P}_{t+1}}-\eta_{1, t+1}^{\beta} v_{t+1}^{\beta}\right) & =0 \\
\frac{\tau^{\beta}}{\mathbb{P}_{t}}+\eta_{1, t}^{\beta} & =0 \\
\frac{1}{b_{1, t}^{\beta}}+\eta_{2, t}^{\beta} & =0 \\
\frac{1}{e_{2, t}^{\beta}-q_{2, t}^{\beta}}+\eta_{2, t}^{\beta} \lambda_{t}^{\beta} p_{2, t}+\beta \mathbb{E}_{t}\left(\eta_{1, t+1}^{\beta} p_{2, t}\left(1-\lambda_{t}^{\beta}\right)\right) & =0 \\
v_{t}^{\beta} \mu_{t-1}^{\beta}-p_{2, t-1} q_{2, t-1}^{\beta}\left(1-\lambda_{t-1}^{\beta}\right) & =0 \\
b_{1, t}^{\beta}-\frac{\mu_{t}^{\beta}}{1+r_{t}^{c}}-\lambda_{t}^{\beta} p_{2, t} q_{2, t}-\frac{1-\phi}{2} \Pi_{t}^{\theta} & =0
\end{aligned}
$$

10.3 FOCs for Bank $\theta$

$$
\begin{aligned}
\frac{1}{\Pi_{t}^{\theta}}+\eta_{1, t}^{\theta}-\phi \eta_{2, t}^{\theta} & =0 \\
-\frac{\eta_{2, t}^{\theta}}{1+r_{t}^{I B}}-\hat{\beta} \mathbb{E}_{t}\left(\frac{\tau^{\theta}\left(1-v_{t+1}^{\theta}\right)}{\mathbb{P}_{t+1}}-\eta_{1, t+1}^{\theta} \frac{v_{t+1}^{\theta}}{\mathbb{P}_{t+1}}\right) & =0 \\
\tau^{\theta}+\eta_{1, t}^{\theta} & =0 \\
-\hat{\beta} \mathbb{E}_{t}\left(\frac{\eta_{1, t+1}^{\theta} R_{t+1}\left(1+r_{t}^{c}\right)}{\mathbb{P}_{t+1}}\right)+\eta_{2, t}^{\theta} & =0 \\
\Pi_{t}^{\theta}-\frac{R_{t} l_{t-1}^{\theta}\left(1+r_{t-1}^{c}\right)}{\mathbb{P}_{t}}+v_{t}^{\theta} \frac{\mu_{t-1}^{\theta}}{\mathbb{P}_{t}} & =0 \\
l_{t}^{\theta}-\frac{\mu_{t}^{\theta}}{1+r_{t}^{I B}}-\phi \Pi_{t}^{\theta} & =0
\end{aligned}
$$


10.4 Market clearing conditions and rational expectations

$$
\begin{aligned}
b_{1, t}^{\beta}-p_{1, t} q_{1, t}^{\alpha} & =0 \\
b_{2, t}^{\alpha}-p_{2, t} q_{2, t}^{\beta} & =0 \\
1+r_{t}^{c}-\frac{\mu_{t}^{\alpha}+\mu_{t}^{\beta}}{l_{t}^{\theta}} & =0 \\
1+r_{t}^{I B}-\frac{\mu_{t}^{\theta}}{M_{t}} & =0 \\
R_{t}-\frac{v_{t}^{\alpha} \mu_{t}^{\alpha}+v_{t}^{\beta} \mu_{t}^{\beta}}{\mu_{t}^{\alpha}+\mu_{t}^{\beta}} & =0
\end{aligned}
$$

\subsection{Equations of shocks}

$$
\begin{gathered}
\mathbb{P}_{t}=\frac{M_{t}}{M_{t-1}} \\
M_{t}=\eta_{t}^{C B} \bar{M} \\
\ln \left(\eta_{t}^{C B}\right)=\rho^{C B} \ln \left(\bar{\eta}^{C B}\right)+\left(1-\rho^{C B}\right) \ln \left(\eta_{t-1}^{C B}\right)+\epsilon_{C B, t} \\
\ln \left(\lambda_{t}^{\alpha}\right)=\rho^{\alpha} \ln \left(\bar{\lambda}^{\alpha}\right)+\left(1-\rho^{\alpha}\right) \ln \left(\lambda_{t-1}^{\alpha}\right)+\epsilon_{\alpha, t}^{\lambda} \\
\ln \left(\lambda_{t}^{\beta}\right)=\rho^{\beta} \ln \left(\bar{\lambda}^{\beta}\right)+\left(1-\rho^{\beta}\right) \ln \left(\lambda_{t-1}^{\beta}\right)+\epsilon_{\beta, t}^{\lambda} \\
\ln \left(e_{1, t}^{\alpha}\right)=\rho_{e}^{\alpha} \ln \left(\bar{e}_{1}^{\alpha}\right)+\left(1-\rho_{e}^{\alpha}\right) \ln \left(e_{1, t-1}^{\alpha}\right)+\epsilon_{\alpha, t}^{e} ; \\
\ln \left(e_{2, t}^{\beta}\right)=\rho_{e}^{\beta} \ln \left(\bar{e}_{2}^{\beta}\right)+\left(1-\rho_{e}^{\beta}\right) \ln \left(e_{2, t-1}^{\beta}\right)+\epsilon_{\beta, t}^{e} ;
\end{gathered}
$$




\section{Appendix 5: Risk aversion sensitivity analysis}

\subsection{Households}
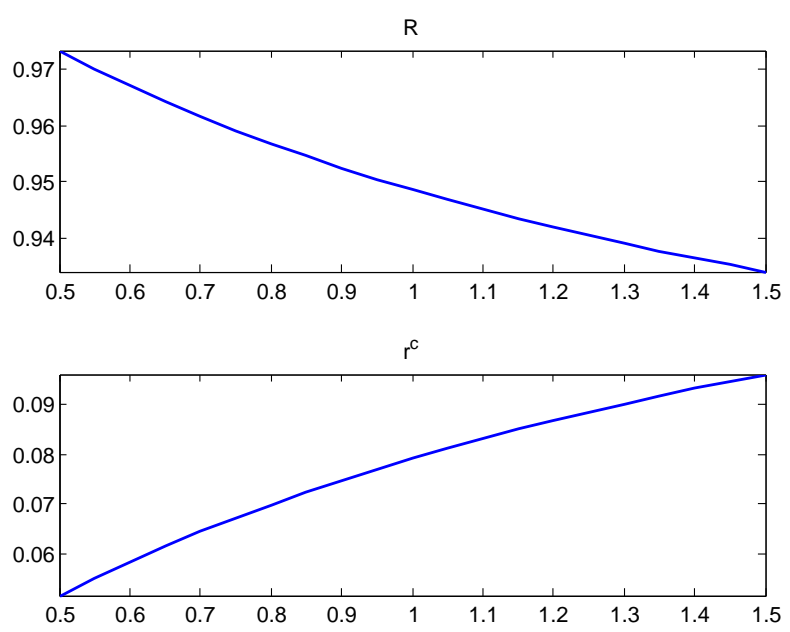

Figure 8: Sensitivity of steady-state levels to risk aversion.

\subsection{Bank}
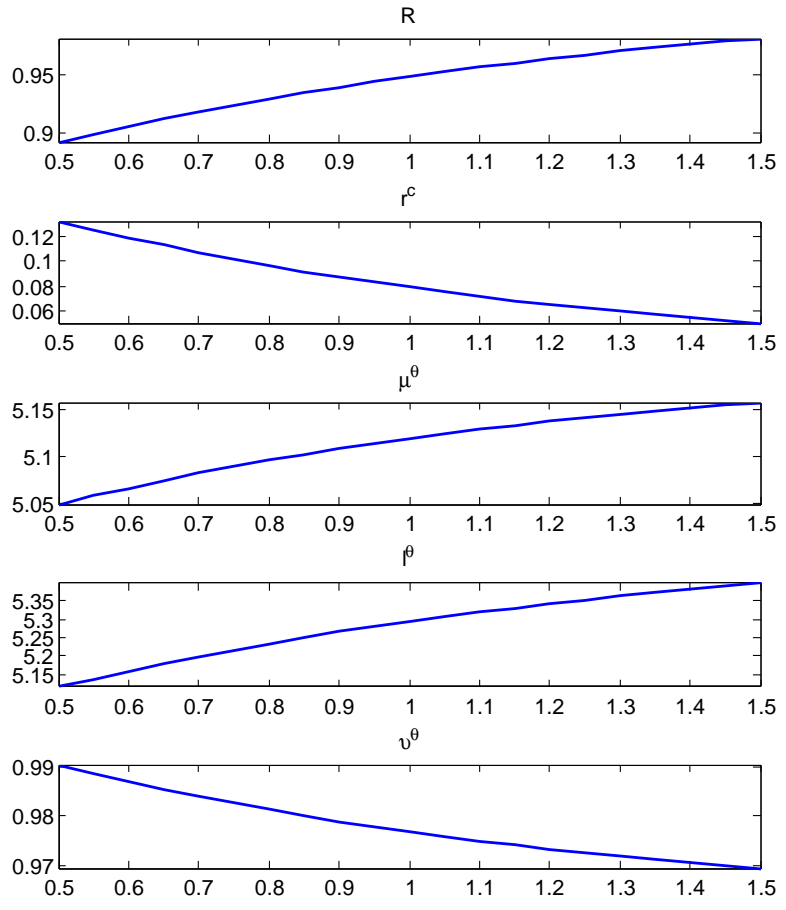

Figure 9: Sensitivity of steady-state levels to risk aversion. 


\section{Appendix 6: Impulse response experiments}

12.1 Shock to funding liquidity or money base $\left(\Delta^{-} 5 \% M\right)$
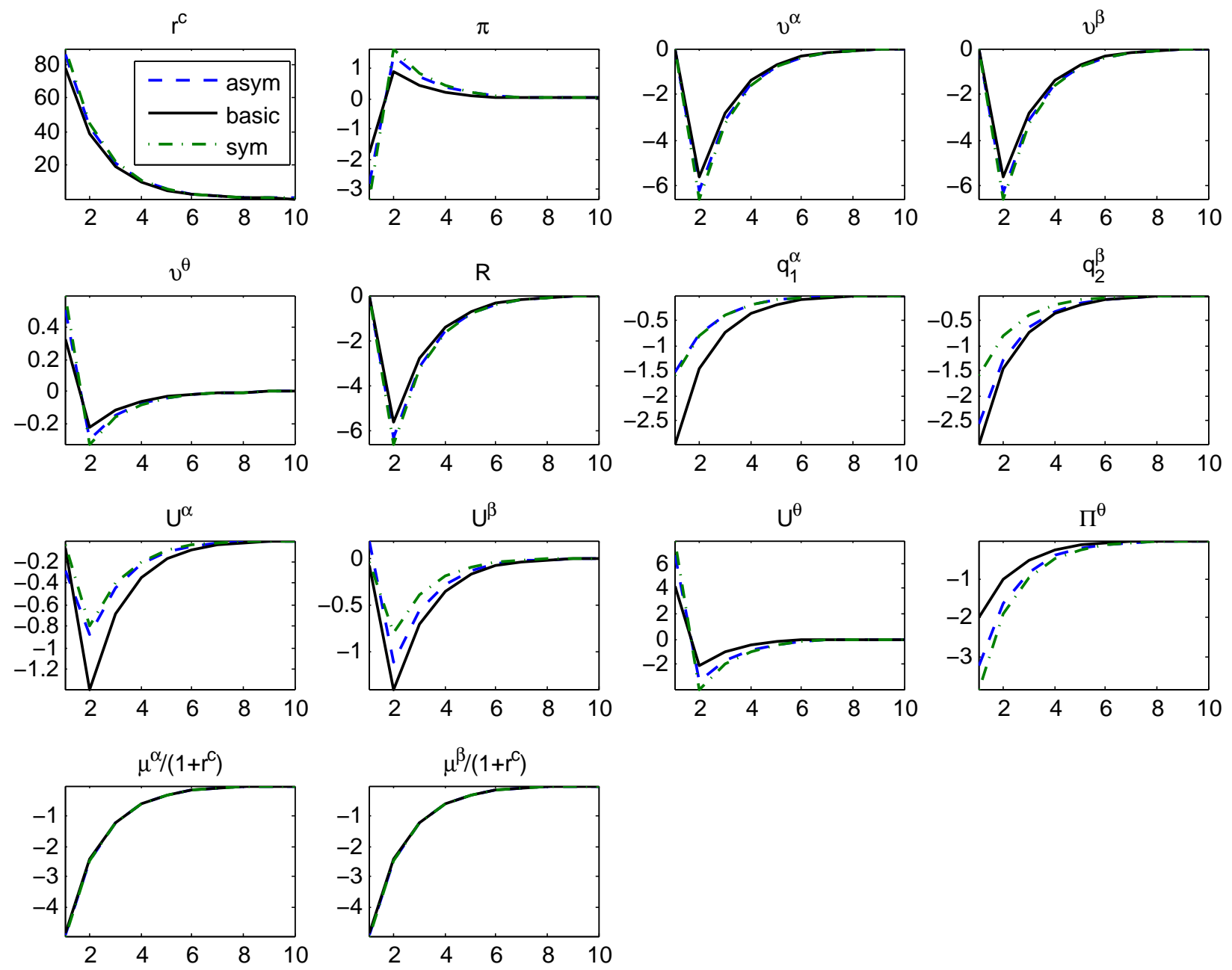

Figure 10: Impulse responses. Percentage variations with respect to steady-state levels (except for inflation in percentage terms). Time in quarters. 


\subsection{Shock to market liquidity $\left(\Delta^{-} 5 \% \lambda^{\alpha}\right)$}
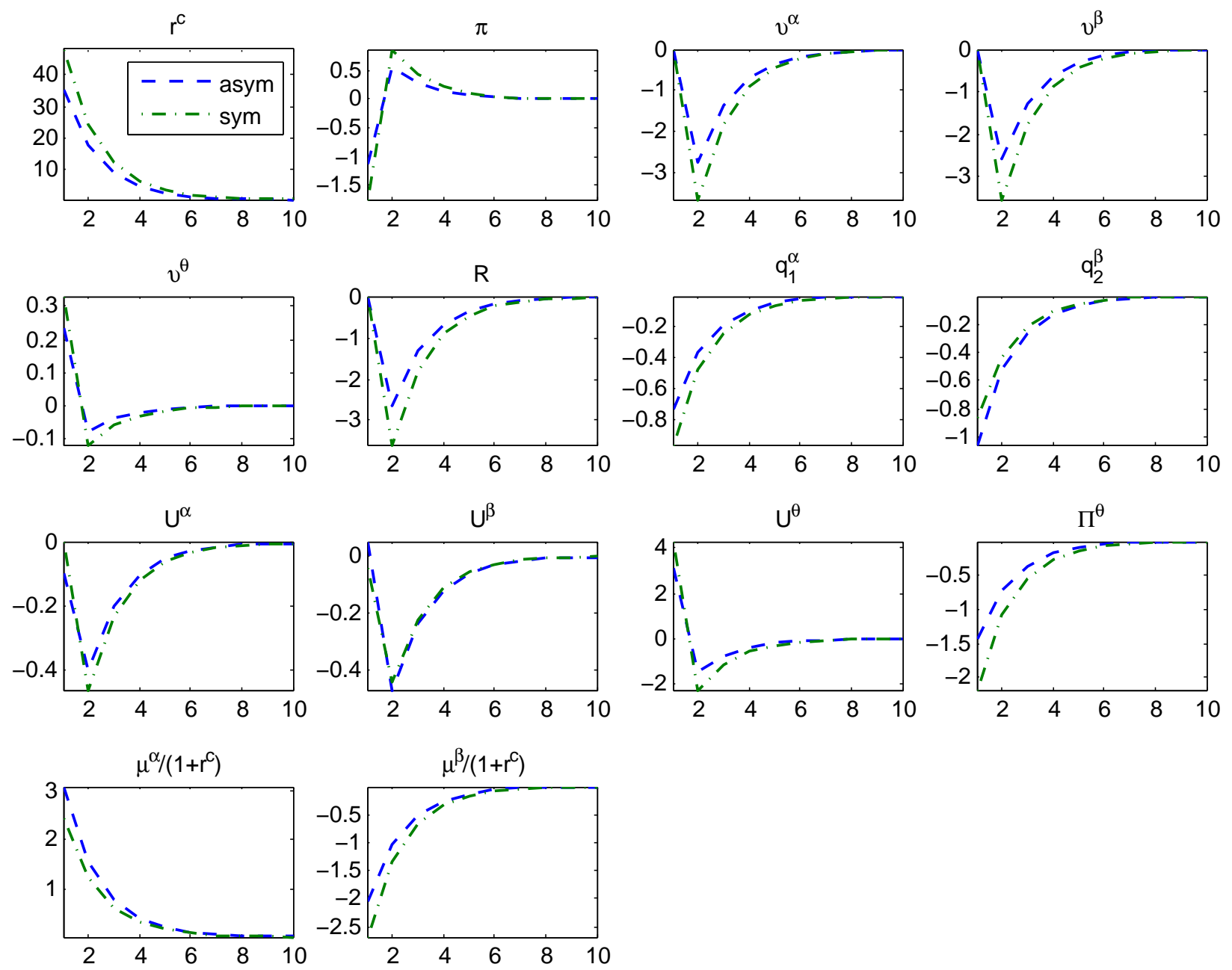

Figure 11: Impulse responses. Percentage variations with respect to steady-state levels (except for inflation in percentage terms). Time in quarters. 


\subsection{Shock to market liquidity $\left(\Delta^{-} 5 \% \lambda^{\beta}\right)$}
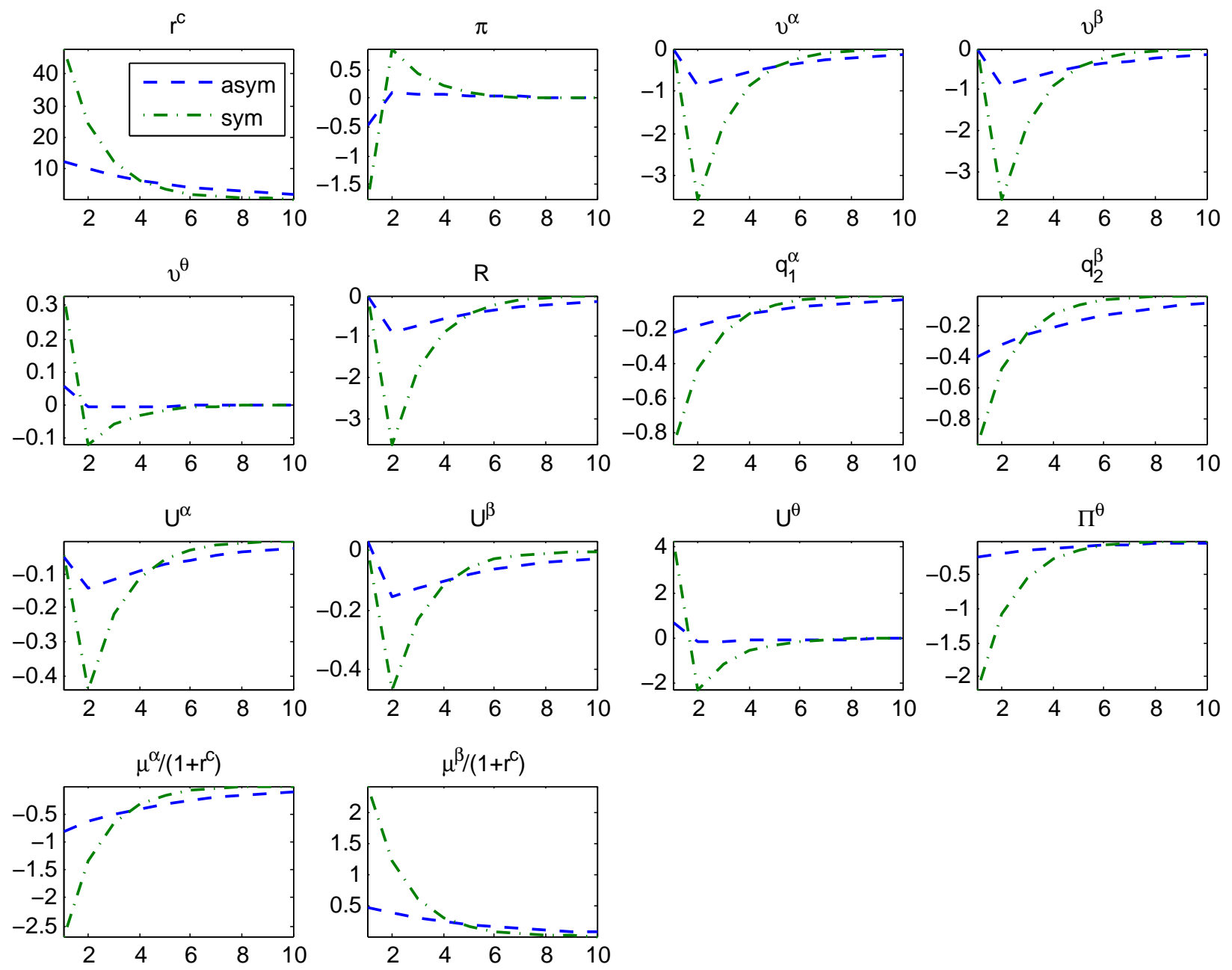

Figure 12: Impulse responses. Percentage variations with respect to steady-state levels (except for inflation in percentage terms). Time in quarters. 


\subsection{Shock to market liquidity $\left(\Delta^{-} 5 \% \lambda^{\alpha}+\lambda^{\beta}\right)$}
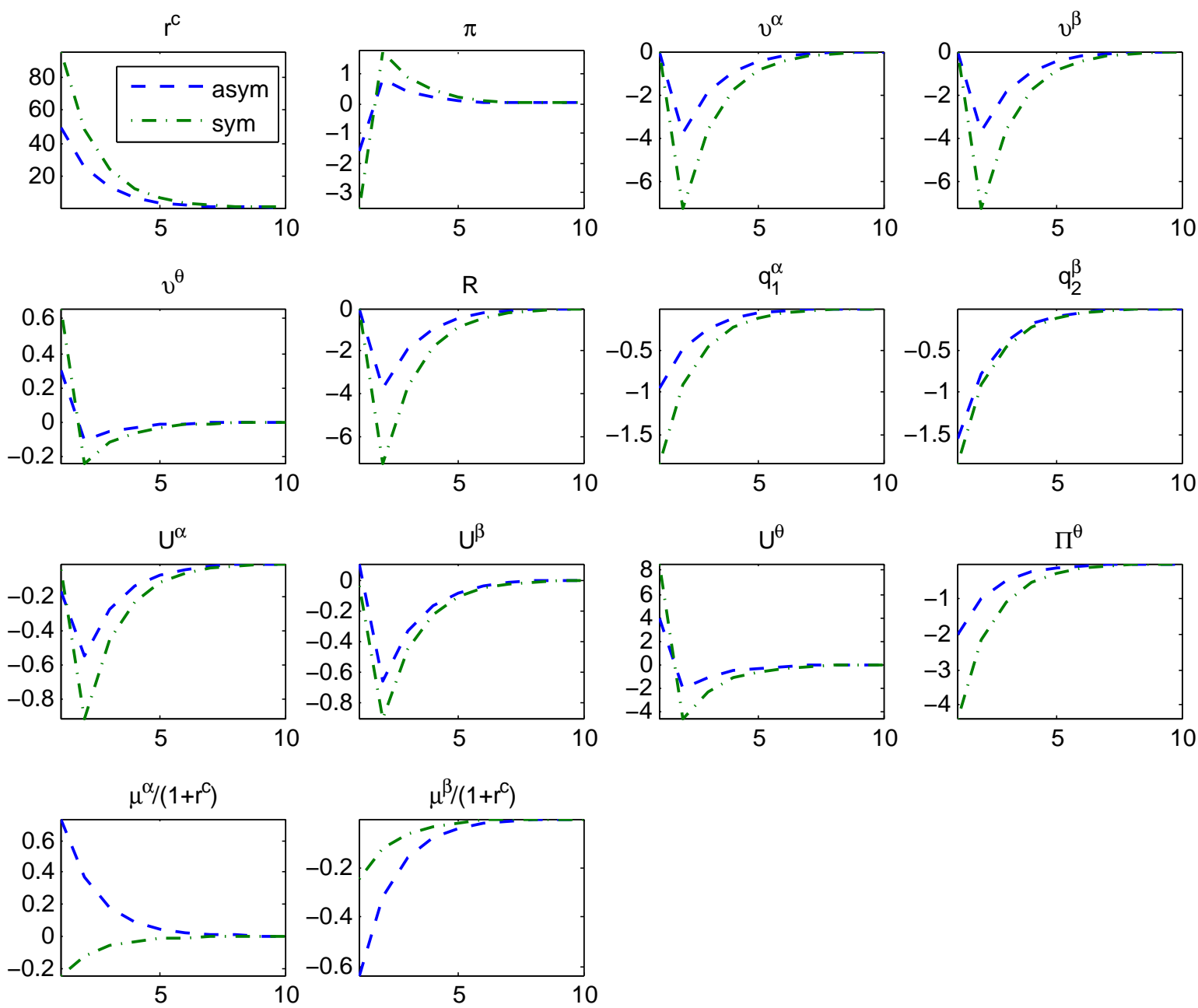

Figure 13: Impulse responses. Percentage variations with respect to steady-state levels (except for inflation in percentage terms). Time in quarters. 


\subsection{Shock to endowment $\left(\Delta^{-} 5 \% e^{\alpha}\right)$}
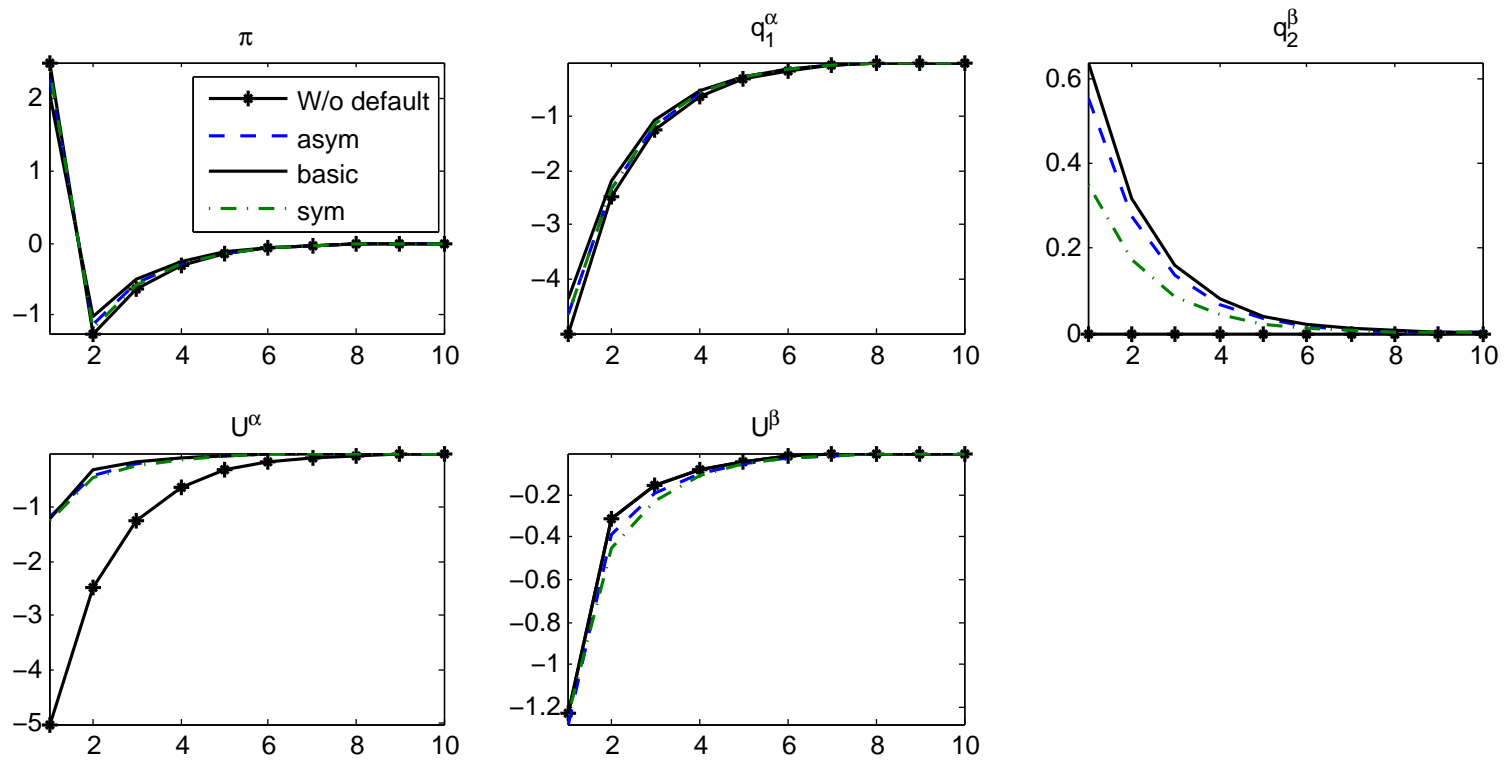

Figure 14: Impulse responses. Percentage variations with respect to steady-state levels (except for inflation in percentage terms). Time in quarters.

\subsection{Shock to endowments $\left(\Delta^{-} 5 \% e^{\alpha}+e^{\beta}\right)$}
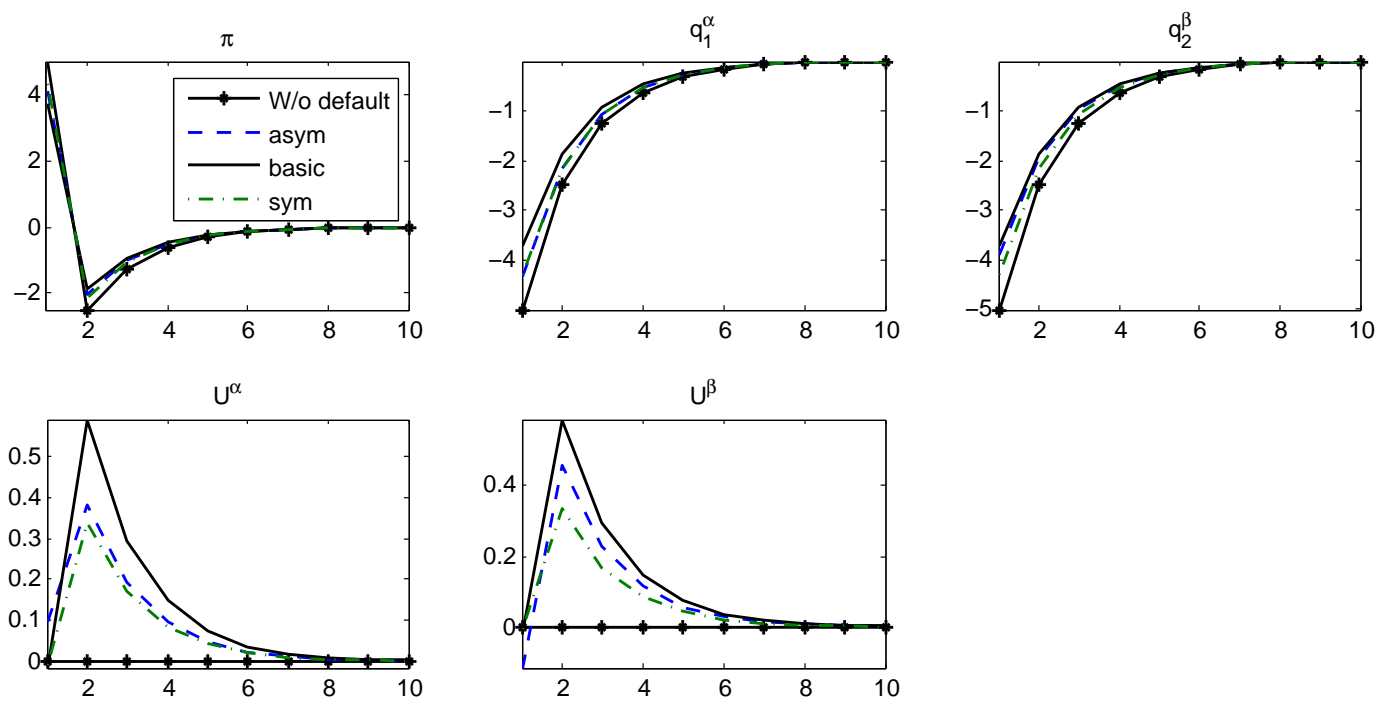

Figure 15: Impulse responses. Percentage variations with respect to steady-state levels (except for inflation in percentage terms). Time in quarters. 